\title{
Hypothalamic NMDA receptors stabilize NREM sleep and are essential for REM sleep
}

\section{Giulia Miracca ${ }^{1}$, Berta Anuncibay Soto ${ }^{1,2}$, Kyoko Tossell ${ }^{1}$,}

\section{Raquel Yustos ${ }^{1}$, Alexei L. Vyssotski ${ }^{3}$, Nicholas P.}

\section{Franks ${ }^{1,2^{*}}$, William Wisden ${ }^{1,2^{*}}$}

${ }^{1}$ Department of Life Sciences and ${ }^{2} U K$ Dementia Research Institute, Imperial College London, London SW7 2AZ, U.K; Institute of Neuroinformatics, University of Zürich/ETH Zürich, Winterthurerstrasse 190, CH-8057, Zürich, Switzerland.

"Co-senior authors: Nicholas P. Franks and William Wisden, Department of Life Sciences, Sir Ernst Chain Building, Imperial College London, South Kensington, London SW7 2AZ, UK.

Email: n.franks@imperial.ac.uk or w.wisden@imperial.ac.uk 


\section{SUMMARY}

The preoptic hypothalamus regulates both NREM and REM sleep. We found that calcium levels in mouse lateral preoptic (LPO) neurons were highest during REM. Deleting the core GluN1 subunit of NMDA receptors from LPO neurons abolished calcium signals during all vigilance states, and the excitatory drive onto LPO neurons was reduced. Mice had less NREM sleep and were incapable of generating conventionally classified REM sleep episodes: cortical theta oscillations were greatly reduced but muscle atonia was maintained. Additionally, mice lacking NMDA receptors in LPO neurons had highly fragmented sleep-wake patterns. The fragmentation persisted even under high sleep pressure produced by sleep deprivation. Nevertheless, the sleep homeostasis process remained intact, with an increase in EEG delta power. The sedative dexmedetomidine and sleeping medication zolpidem could transiently restore consolidated sleep. High sleep-wake fragmentation, but not sleep loss, was also produced by selective GluN1 knock-down in GABAergic LPO neurons. We suggest that NMDA glutamate receptor signalling stabilizes the firing of "GABAergic NREM sleep-on" neurons and is also essential for the theta rhythm in REM sleep. 


\section{INTRODUCTION}

Many people suffer from occasional insomnia, but it can develop into a debilitating condition (Roth et al., 2011). Insomnia, as a clinical disorder, is defined as an inability to initiate or maintain sleep at least three times a week over three months, even when sleep conditions are otherwise optimal (Van Someren, 2020). Insomniacs frequently report that their sleep is non-restorative and that they sleep less. In fact, insomnia sufferers often have the same amounts of EEG-defined NREM sleep as controls, but oscillate frequently between wake and NREM sleep, so that their sleep is fragmented, and often their REM sleep is disturbed (Van Someren, 2020). For self-reported sleep quality, good sleep continuity and increased length REM sleep were found to give the best subjective sleep quality (Della Monica et al., 2018). Even if sleep is poor, wakefulness still cannot be sustained beyond a certain limit. This limit is thought to be imposed by the process of sleep homeostasis, also named Process $S$, the increasing drive to enter NREM sleep as wakefulness continues (Borbely et al., 2016). S then declines as sleep progresses.

Both NREM and REM sleep are in part controlled by the preoptic (PO) hypothalamus (Lu et al., 2002; Lu et al., 2000; McGinty and Sterman, 1968; Nauta, 1946; Sherin et al., 1996; Szymusiak et al., 2007). In this structure, GABA/peptidergic neurons, e.g. GABA/galanin neurons, contribute to NREM sleep induction and sleep homeostasis (Chung et al., 2017; Kroeger et al., 2018; Ma et al., 2019; Reichert et al., 2019; Sherin et al., 1996; Zhang et al., 2015). To stay asleep, and prevent insomnia, it seems reasonable to assume that these sleep-promoting neurons would have to stay "on". Indeed, lesioning of lateral (LPO) neurons in rats reduces the amounts of NREM or REM sleep, depending on the lesion's location (Lu et al., 2000). But factors that keep LPO sleep-promoting neurons firing and so govern the lengths of NREM and REM sleep episodes are not known.

In both insects and mammals, calcium entry through NMDA-type ionotropic glutamategated receptors has been proposed to signal the sleep homeostatic process, in an analogous 
mechanism to changing synaptic strength that underlies memory formation (Liu et al., 2016; Raccuglia et al., 2019; Tatsuki et al., 2016). These studies provided our initial motivation for the experiments reported here. We wanted to test if NMDA receptors mediate the homeostatic sleep drive in the PO hypothalamus. Consistent with the hypothesis, NMDA receptor activation promotes sleep. In the fruit fly Drosophila, genetic knockdown of NMDA receptors in brain reduces total sleep time (Tomita et al., 2015). In rodents, NMDA receptor antagonists reduce and agonists enhance NREM sleep (Burgdorf et al., 2019; Tatsuki et al., 2016). Furthermore, patients with autoimmunity to the core and essential GluN1 subunit of NMDA receptors often suffer severe insomnia (Arino et al., 2020; Dalmau et al., 2019). Because NMDA receptors are near universally expressed in the brain (Monyer et al., 1994; Moriyoshi et al., 1991), these effects on sleep could come from interference with many circuits.

In this study, we deleted the GluN1 NMDA receptor subunit in the LPO hypothalamus and find that NMDA receptors there are not involved in sleep homeostasis. Instead, we obtained an unexpected "insomnia" phenotype with high sleep-wake fragmentation and greatly diminished REM sleep. This implicates a new signaling pathway in maintaining the consistency of NREM sleep and generating REM sleep. The sleep-wake fragmentation effect is selective for the GluN1 expression in GABA neurons. We suggest that NMDA glutamate receptor signalling, perhaps because of the long open times of this type of channel, stabilizes the firing of hypothalamic "GABAergic sleep-on" neurons for consolidated sleep. 


\section{RESULTS}

\section{CALCIUM ACTIVITY IN LPO HYPOTHALAMIC NEURONS IS HIGHEST DURING REM SLEEP}

We first recorded calcium activity in LPO hypothalamic neurons using photometry with GCaMP6s expressed under the control of a universally active promoter. Mice were injected in LPO with AAV-GCaMP6s (Figure 1A-B). Highest calcium activity occurred during REM sleep episodes, especially at the beginning and end of the episodes (Figure 1C-D). During NREM sleep, LPO neurons showed a more sporadic and spikey activity, and during wakefulness only low activity. By plotting scaled means of GCaMP6s signal against EMG signal (Figure 1E, left panel) and delta power (Figure 1E, centre panel), REM sleep episodes were distributed towards higher values of GCaMP6s signal, separating them from the NREM sleep and wake data points. Comparing the average of $\Delta F / F$ points during each behavioural state, REM sleep calcium values were significantly higher than in other vigilance states (Figure 1E, right panel).

Photometry recordings were also performed in different subtypes of LPO hypothalamic neurons by injecting $A A V$-flex-GCaMP6s into the LPO area of Vgat-Cre, Vglut2-Cre, Nos1Cre and Galanin-Cre mice (Supplementary Figure 1A-C). As for the pan-neuronal recordings, the subsets of LPO neuronal populations all showed a significantly higher calcium activity during REM sleep episodes compared with NREM sleep and wake (Figure 1F).

\section{DELETION OF NMDA RECEPTORS FROM LPO NEURONS ABOLISHES CALCIUM SIGNALS}

NMDA receptors assemble as heteromeric tetramers of subunits, with two core GluN1 subunits, whose gene grin1 is transcribed universally in the brain (Moriyoshi et al., 1991), and GluN2 and/or GluN3 subunits, whose genes are differentially expressed (Monyer et al., 1994; Monyer et al., 1992; Paoletti et al., 2013). GluN1 is essential for all NMDA receptors (Paoletti et al., 2013; Tsien et al., 1996). Mice homozygous for a conditional allele (floxed-Grin1) that 
encodes the GluN1 subunit were bilaterally injected into the LPO hypothalamus with $A A V$ Cre-2A-Venus, generating $\triangle$ GluN1-LPO mice (Figure $2 \mathrm{~A}$ ). More than $75 \%$ of the cells expressing the AAV-Cre-2A-Venus transgene were in LPO (Supplementary Figure 2A-C). Microglia and astrocytes were not transduced with the particular AAV (AAV1/2) serotype, as there was no co-expression of Venus and the astrocyte marker GFAP or the microglial marker IBA1 (Supplementary Figure 2D).

We examined if NMDA receptor currents were deleted from $\triangle$ GluN1-LPO neurons compared to control mice injected with AVV-GFP by recording evoked excitatory post-synaptic currents (eEPSCs) from ex-vivo acute slices prepared from the PO area (Supplementary Figure 2E and F). eEPSCs on LPO neurons consist of both a slow (hundreds of milliseconds) NMDA and fast (few millisecond) AMPA receptor component (Figure 2B). On LPO neurons from $\triangle$ GluN1-LPO mice, the slow NMDA component was eliminated (Figure 2B). Deletion of the NMDA-mediated current from LPO neurons also reduced spontaneous excitatory postsynaptic current (sEPSCs) amplitudes (Supplementary Figure $2 \mathrm{H}$ ) and frequency (Supplementary Figure 2I).

We tested how NMDA deletion from LPO neurons influenced intracellular calcium. We co-injected into the LPO area of floxed-Grin1 gene mice AAV-Cre-Cherry and AAV-flex GCaMP6s, so that only neurons expressing Cre recombinase express the calcium sensor (Figure 2C). Regardless of vigilance state, calcium activity in $\triangle$ GluN1-LPO neurons was greatly reduced (Figure 2D and E), and REM sleep was no longer highlighted by calcium activity, showing that deleting NMDA receptors ablates calcium fluctuations from LPO neurons.

\section{DELETION OF NMDA RECEPTORS FROM LPO NEURONS REDUCES NREM AND REM SLEEP AND PRODUCES HIGH SLEEP-WAKE FRAGMENTATION}

We examined the effect of the GluN1 LPO deletion on vigilance states (Figure 3A). Throughout 24h, $\Delta$ GluN1-LPO mice compared with GFP-LPO (Figure 3B) mice spent more 
time awake (Figure 3C and D). $\triangle$ GluN1-LPO mice lost on average $15-20 \%$ of NREM sleep time and $50 \%$ of their REM sleep time during both light and dark periods (Figure 3D). EEG power spectra for wake and NREM were similar between control and $\triangle$ GluN1-LPO mice (Figure 3E); however, $\triangle$ GluN1-LPO mice had strongly reduced cortical theta oscillations during REM sleep episodes (5-10 Hz, Figure 3E, right panel). Consequently, EEG and EMG recordings during REM sleep episodes (Supplementary Figure $3 \mathrm{~A}$ and $\mathrm{B}$ ) showed a reduced theta:delta power (T:D) ratio in $\triangle$ GluN1-LPO mice compared to GFP-LPO controls (Supplementary Figure 3C), although atonia was maintained in both groups.

In addition to sleep loss and reduced cortical theta power, $\triangle$ GluN1-LPO mice had a highly fragmented sleep-wake phenotype: they lacked long wake and NREM sleep episodes, as they had significantly more wake and NREM sleep episodes (Figure 3F, left panel), with a decrease in their mean duration (Figure 3F, centre panel). Indeed, removing the NMDA receptor from LPO neurons increased transitions between wake and NREM sleep by $>55 \%$ (Figure 3F, right panel). The phenotype occurred in both the light and dark phases (Figure 3F). For REM sleep in $\triangle$ GluN1-LPO mice, there was a 50 to $70 \%$ decrease in episode number, mean duration and transitions to and from this vigilance state (Figure $3 \mathrm{~F}$ ).

\section{REGION-SPECIFIC EFFECT OF NMDA RECEPTOR ABLATION ON SLEEP-WAKE FRAGMENTATION}

We also tested if deleting the GluN1 subunit in a region neighbouring the PO area, the anterior hypothalamic area (AHA), caused sleep loss or fragmentation (Supplementary Figure 4A-C). Bilateral injection of AAV-Cre-Venus and AAV-GFP into the AHA of floxed-grin1 mice, to generate $\triangle$ GluN1-AHA and GFP-AHA animals respectively, did not affect sleep and wake amounts during either the light or dark phases (Supplementary Figure 4A-C), nor did the deletion influence the number of transitions between vigilance states (Supplementary Figure 4D). $\triangle$ GluN1-AHA mice did not show any signs of sleep fragmentation: the episode number of NREM and REM sleep epochs and their mean duration were similar to GFP-AHA animals 
bioRxiv preprint doi: https//doi.org/10.1101/2020.10.19.345728; this version posted October 20, 2020. The copyright holder for this preprint (which was not certified by peer review) is the author/funder, who has granted bioRxiv a license to display the preprint in perpetuity. It is made available under aCC-BY-NC 4.0 International license.

(Supplementary Figure 4E). Therefore, the fragmented sleep phenotype produced by deleting NMDA receptors originates region-selectively in the hypothalamus.

\section{THE INSOMNIA OF $\Delta$ NR1-LPO MICE PERSISTS UNDER HIGH SLEEP PRESSURE}

To investigate if the fragmented sleep of $\Delta$ GluN1-LPO mice persisted under high sleep pressure and if NMDA receptors in LPO were required for sleep homeostasis, we performed $6 \mathrm{~h}$ of sleep deprivation (SD) at the onset of the "lights on" period when the sleep drive is highest (Figure 4A). Although $\triangle \mathrm{NR} 1$-LPO mice were awake and moving during the sleep deprivation, there were several indications that they were under high sleep pressure. During the sleep deprivation, the EEG theta power in $\triangle$ NR1-LPO mice was greatly reduced (red trace in Figure 4B when compared with GFP-LPO animals), and most of the power was concentrated in the delta frequency band (Figure 4B). Compared to GFP-LPO mice, $\Delta$ GluN1LPO mice had many more sleep attempts during the sleep deprivation procedure (Figure 4C, left panel), and at the end of the 6 hour procedure they had a shorter latency to fall asleep (Figure 4C, right panel).

During the subsequent first hour of sleep following sleep deprivation, both $\Delta$ GluN1LPO and GFP-LPO mice had a significant increase in NREM delta power compared to their own baseline at the same circadian time (Figure 4D and E, left panels), showing that by this measure, sleep homeostasis was intact. The typical diurnal variation in EEG delta power over 24 hours seen in control mice was also still present in $\triangle$ GluN1-LPO mice (Figure 4D and E right panels). However, $\triangle$ GluN1-LPO mice were incapable of recuperating the sleep lost during sleep deprivation (Figure 4F). Following sleep deprivation as a percentage over their own baselines, GFP-LPO mice as expected increased their time asleep, reducing time spent awake. $\Delta$ GluN1-LPO animals, however, did not (Figure 4F). After sleep deprivation, $\Delta$ GluN1LPO animals maintained a highly fragmented sleep phenotype during their recovery sleep, as shown by the over 2-fold increase over GFP-LPO mice in the number of transitions between NREM sleep and wake during the $18 \mathrm{~h}$ sleep recovery opportunity time (Figure $4 \mathrm{G}$ ). Additionally, NREM and wake episodes numbers were still increased, and mean duration 
decreased in $\triangle$ GluN1-LPO mice after SD, whereas REM sleep values were still consistently lower than in GFP-LPO mice (Figure 4H). The persistence of fragmentation after SD in $\triangle$ GluN1-LPO mice is particularly noteworthy, as under increased sleep pressure, quantified by the delta power rebound, sleep is deeper compared to baseline levels. These data suggest that $\Delta$ GluN1-LPO mice were extremely sleepy but could not stay asleep.

\section{SEDATIVES AND SLEEPING MEDICATION TRANSIENTLY IMPROVE SLEEP QUALITY OF $\triangle$ NR1-LPO MICE}

We investigated whether drugs that induce NREM-like sleep, dexmedetomidine which is used in intensive care units for long-term sedation (Adams et al., 2013), and zolpidem (Ambien), a widely prescribed sleeping medication (Wisden et al., 2019), could reduce the high sleep fragmentation in $\triangle$ GluN1-LPO animals and restore consolidated sleep. Following i.p. injection of $\Delta$ GluN1-LPO animals, both dexmedetomidine (25 and $50 \mu \mathrm{g} / \mathrm{kg}$ ) and zolpidem $(5 \mathrm{mg} / \mathrm{kg})$ increased the time spent asleep (Figure $5 \mathrm{~A}$ and B). $50 \mu \mathrm{g} / \mathrm{kg}$ of dexmedetomidine reduced the number of NREM sleep episodes and increased NREM episode mean duration for $1 \mathrm{~h}$ after injection (Figure $3 \mathrm{C}$ left and right panels). Sleep-wake transitions were also reduced under both doses of dexmedetomidine (Figure 5D). On the other hand, zolpidem did not affect the number of NREM sleep episodes, but it increased their duration (Figure 5E, right and left panel), resulting in a decrease in transitions between behavioural states (Figure 5F). For both drugs, a few hours after administration the highly fragmented sleep pattern reemerged (data not shown).

\section{SLEEP FRAGMENTATION BUT NOT SLEEP LOSS IS PRODUCED BY SELECTIVE NMDA GIuN1 SUBUNIT KNOCK-DOWN IN GABA LPO NEURONS.}

We identified an shRNA to selectively reduce GluN1 expression cell type selectively, for example, in GABAergic or glutamatergic cells in LPO. The efficacy of shRNAs to knockdown recombinant GluN1 cDNA expression was selected in vitro (Figure 6A and B). Having identified a suitable shRNA, AAV-flex-shRNA-GluN1 and AAV-flex-shRNA-scramble were 
bioRxiv preprint doi: https://doi.org/10.1101/2020.10.19.345728; this version posted October 20, 2020. The copyright holder for this preprint (which was not certified by peer review) is the author/funder, who has granted bioRxiv a license to display the preprint in perpetuity. It is made available under aCC-BY-NC 4.0 International license.

bilaterally injected into the LPO areas of Vgat-Cre and Vglut2-Cre mice (Figure 6C and Supplementary Figure $5 \mathrm{~A}$ ). Unlike the $\triangle \mathrm{GluN1-LPO}$ mice, the overall macrostructure of vigilance states was not changed by GluN1 knockdown in GABA or glutamate neurons: VgatshRNA-GluN1 and Vglut2-shRNA-GluN1 mice did not have sleep loss compared with the respective scramble shRNA controls (Figure 6D and Supplementary Figure 5B). The EEG power spectra during wake, NREM and REM sleep were also not different, and there were no disruptions in REM sleep (Figure 6E and Supplementary Figure 5C). However, knock-down of the GluN1 subunit from LPO-Vgat neurons, but not LPO-Vglut2 neurons (Supplementary Figure 5D), caused a strong sleep-wake fragmentation phenotype (Figure 6F). For VgatshRNA-GluN1 mice, there were more episodes (Figure 6F, left panel), and decreases in episode duration (Figure 6F, centre panel), resembling the sleep fragmentation phenotype observed in $\triangle$ GluN1-LPO mice. There was a $>55 \%$ increase in transitions between vigilance states in Vgat-shRNA-GluN1 animals compared with Vgat-shRNA-scr mice (Figure 6F, right panel), as $\Delta$ GluN1-LPO mice compared to their controls.

As for the $\Delta$ GluN1-LPO mice, we next tested if the sleep-wake fragmentation phenotype of Vgat-shRNA-GluN1 mice persisted under conditions of strong sleep pressure following $6 \mathrm{hr}$ of sleep deprivation. In contrast to pan-neuronal GluN1 deletion, Vgat shRNA-GluN1 animals did not show a "sleepy phenotype", as their sleep attempts during sleep deprivation did not differ from the control group (Supplementary Figure 6A). Following 6hSD, Vgat-shRNA-GluN1 mice had a significant increase in the EEG delta power during the $1 \mathrm{~h}$ following SD compared to their own baseline power, similarly to $\triangle$ NR1-LPO mice, showing that sleep homeostasis was intact (Supplementary Figure 6B). Vgat-shRNA-GluN1 mice maintained the fragmented sleep phenotype even under high sleep pressure, with more transitions (Supplementary Figure 6C), and more wake and NREM episodes (Supplementary Figure 6D) with decreased mean durations (Supplementary Figure 6E) compared with Vgat-shRNA-scr animals. Thus, the sleep-wake fragmentation aspect, but not the REM sleep loss, of $\Delta$ GluN1-LPO mice originates from GABA cells in LPO. 


\section{DISCUSSION}

The LPO hypothalamus is required for both NREM and REM sleep generation and NREM sleep homeostasis (Lu et al., 2002; Lu et al., 2000; Ma et al., 2019; McGinty and Sterman, 1968; Nauta, 1946; Reichert et al., 2019; Sherin et al., 1996; Szymusiak et al., 2007; Zhang et al., 2015). We explored how NMDA receptors on LPO neurons regulate sleep. We found that calcium levels in mouse LPO neurons, regardless of cell type, were highest and most sustained during REM sleep, although there was some "spikey activity" during NREM sleep. Deleting the core GluN1 subunit of NMDA receptors from LPO neurons substantially reduced the excitatory drive onto these cells and abolished calcium signals during all vigilance states. These $\triangle$ GluN1-LPO mice had less NREM sleep and no conventional REM sleep (atonia was present, but there was no EEG theta activation). In addition, $\triangle$ GluN1-LPO mice had highly fragmented sleep-wake: they had many more episodes of wake and NREM sleep, but each episode was shorter. Thus, AMPA glutamate receptor excitation alone on LPO sleeppromoting neurons is insufficient to maintain NREM sleep or produce REM sleep. The phenotype was further stratified. High sleep-wake fragmentation, but not sleep loss, was produced by selective GluN1 knock-down in GABAergic LPO neurons. The $\triangle$ GluN1-LPO mice phenotype is quite similar (wake-NREM fragmentation, loss of REM sleep) to mice with a double (global) deletion of the muscarinic receptor genes Chrm1 and Chrm3 (Niwa et al., 2018), so presumably this could intersect on the same pathway.

Our initial motivation for this study was testing the role of NMDA receptors in sleep homeostasis mediated by the PO hypothalamus. Calcium entry through NMDA receptors has been suggested to be part of the sleep homeostasis mechanism that tracks time spent awake (Liu et al., 2016). The sleep homeostasis process is reflected by changes in EEG delta power (Borbely et al., 2016). During the 24 hour cycle, delta power is highest during the "lights on" sleep phase and declines as each NREM sleep bout progresses (Figure 4D, E), which is thought to reflect the dissipation of the homeostatic sleep drive (Borbely et al., 2016). After sleep deprivation, neocortical activity in the subsequent ("recovery") NREM sleep is deeper 
(more synchronised and thus has a higher delta power). However, we found that NMDA receptor deletion in LPO did not affect sleep homeostasis as defined by the classical criteria EEG delta power showed its usual variation, increase and decrease over 24 hours. Even placing $\triangle$ GluN1-LPO mice under high sleep pressure by sleep deprivation did not enable the mice to sleep well. The sleep fragmentation persisted even during the recovery sleep, and the fragmented sleep started off with a higher delta power as expected for recovery sleep in the sleep homeostasis model. So, the sleep homeostatic process seems independent of the mechanism maintaining consolidated sleep. In fact, during sleep deprivation, $\triangle$ GluN1-LPO mice made multiple attempted entries to sleep. It is as if the mice were chronically sleepy, but they could not stay asleep.

Behavioural therapy is often ineffective for treating severe insomnia disorder, and medication remains an alternative approach if used cautiously (Shahid et al., 2012; Van Someren, 2020). Unlike sleep deprivation, which is usually efficient at inducing sleep, drugs could treat quite effectively the insomnia of $\Delta$ GluN1-LPO mice. Dexmedetomidine could transiently restore consolidated NREM sleep. Dexmedetomidine, an $\alpha 2$ adrenergic agonist, induces stage 3 NREM sleep in humans and NREM-like sleep in animals (Akeju et al., 2018; Gelegen et al., 2014; Zhang et al., 2015), and requires galanin/GABA neurons in LPO for its effects (Ma et al., 2019). Zolpidem (Ambien), a GABA ${ }_{A}$ receptor positive modulator, is a widely prescribed sleeping medication (Wisden et al., 2019). Its main effect in humans is to reduce latency to NREM sleep rather than maintaining consolidated sleep. Nevertheless, it did have an effect on $\triangle$ GluN1-LPO mice, restoring longer periods of NREM sleep, although not blocking the fragmentation.

Our findings demonstrate a novel aspect of REM sleep generation. REM sleep is characterized by a high theta delta ratio in the EEG and muscle atonia. In rodents, the theta itself detected in the cortical EEG seems to originate mostly from the hippocampus. Indeed, the theta activation during REM is required for memory processing (Boyce et al., 2016; Izawa et al., 2019). Although the brainstem circuitry that generates muscle atonia during REM sleep 
bioRxiv preprint doi: https//doi.org/10.1101/2020.10 19.345728; this version posted October 20, 2020. The copyright holder for this preprint (which was not certified by peer review) is the author/funder, who has granted bioRxiv a license to display the preprint in perpetuity. It is made available under aCC-BY-NC 4.0 International license.

is reasonably well understood, the circuitry that produces the wake-like activation (theta activity in the EEG) of the neocortex during REM sleep is only partially characterized, seeming to require distributed circuitry throughout the forebrain (Izawa et al., 2019; Luppi et al., 2017; Peever and Fuller, 2016; Renouard et al., 2015; Yamada and Ueda, 2019), including the MCH NREM-REM promoting neurons in the lateral hypothalamus (Jego et al., 2013), and REM-off and REM-on neurons in the dorsal medial hypothalamus (Chen et al., 2018), and GABA and cholinergic neurons in the medial septum which project to the hippocampus (Yoder and Pang, 2005). Although LPO has long been known to be required for REM sleep (Lu et al., 2002; Lu et al., 2000), we were surprised to discover that LPO neurons, regardless of type (e.g. galanin, Vgat, Vglut2), have actually their highest calcium activity during REM sleep. We found that GluN1 knockdown in GABA cells of LPO did not influence REM sleep, whereas the pan knockout in all LPO neurons did, so the cell type(s) responsible for REM sleep generation in LPO require further investigation.

NMDA receptor properties could be responsible for maintaining NREM and REM sleep promoting LPO neurons in the "on" state. As well as calcium permeability, NMDA receptors have a voltage-dependent magnesium block, and in contrast to AMPA-gated ionotropic glutamate receptors, with which they are often paired in synapses, stay open from around 100 msec to $1 \mathrm{~s}$ (Paoletti et al., 2013). Because of these properties NMDA receptors are famously studied for their role in synaptic plasticity, and this is the thinking behind why NMDA receptors would be involved in sleep homeostasis (Liu et al., 2016; Raccuglia et al., 2019). But these same properties also allow NMDA receptors to act as pacemakers, controlling rhythmic firing e.g. in those circuits involved in breathing, swimming and walking (Li et al., 2010; Steenland et al., 2008). It is also possible that the long open times of NMDA receptors stabilize the sleepon neurons in their firing mode. It will be interesting to see if this role of NMDA receptors generalizes to other sleep-promoting circuits. For example, we previously found that genetic silencing of mouse lateral habenula neurons with tetanus toxin light chain produced high NREM sleep-wake fragmentation with conserved amounts of total sleep and wake, with the 
fragmentation effect mostly occurring during the "lights-on" sleep phase (Gelegen et al., 2018). It seems likely that disrupting NMDA receptors on these cells would also produce insomnia, given that that NMDA receptors are needed to keep lateral habenula cells in burst firing (active) mode (Cui et al., 2019; Yang et al., 2018).

In conclusion, we have found that cells in the LPO hypothalamus have their highest calcium activity during REM sleep. This calcium is determined by NMDA receptors. Reducing NMDA receptors in the LPO hypothalamic area causes profound insomnia (wake-NREM sleep fragmentation) and substantial loss of theta activity during REM sleep. Thus, glutamate activation, via NMDA receptors, is essential for NREM sleep maintenance, and drives a key characteristic of REM sleep (theta power).

\section{ACKNOWLEDGEMENTS}

Funded by the Wellcome Trust (107839/Z/15/Z, N.P.F. and 107841/Z/15/Z, W.W.), the UK Dementia Research Institute (N.P.F. and W.W.), and an Imperial College Schrödinger Scholarship (G.M.). 
bioRxiv preprint doi: https//doi.org/10.1101/202010.19.345728; this version posted October 20, 2020. The copyright holder for this

\section{MAIN FIGURES}

A

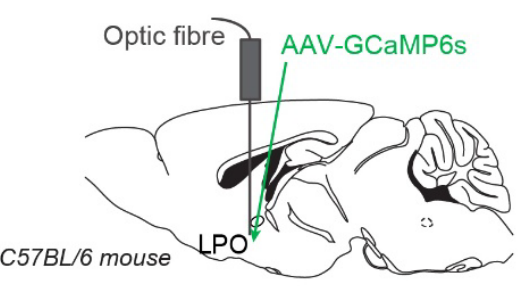

C

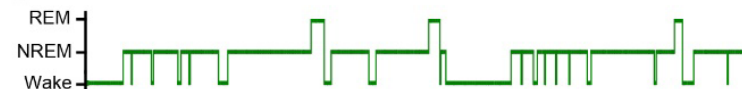

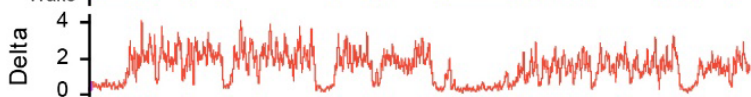

(1) 750$]$
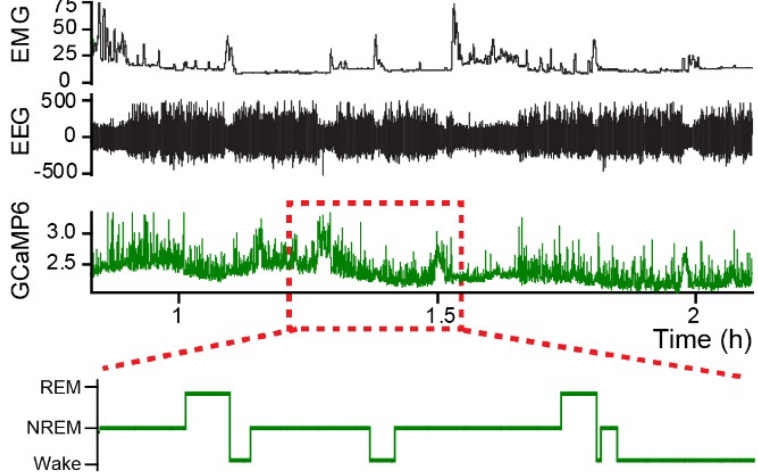

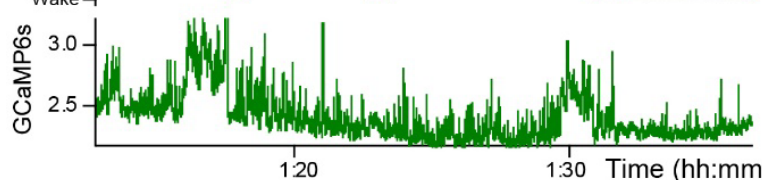

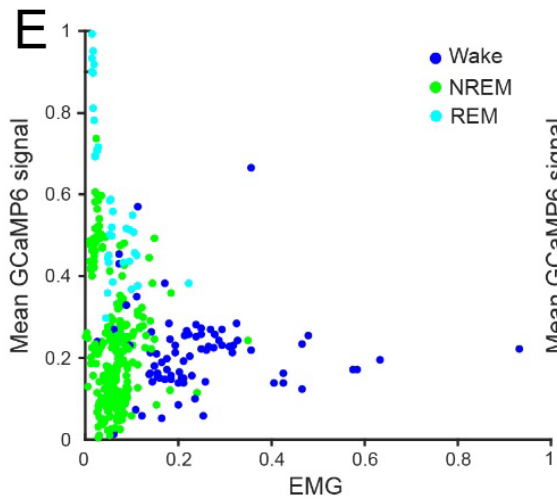

$\mathrm{F}$
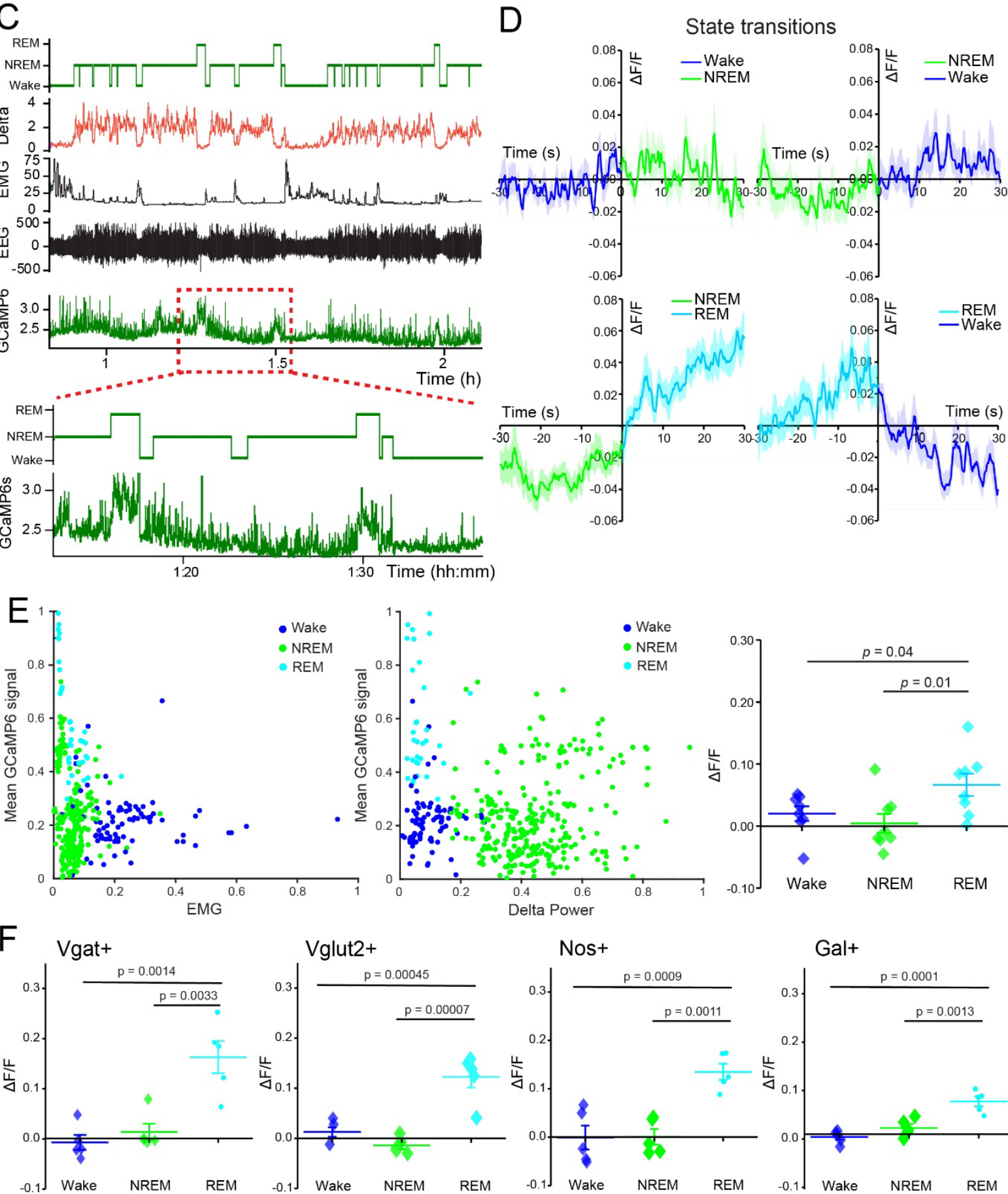

Nos+

Gal+
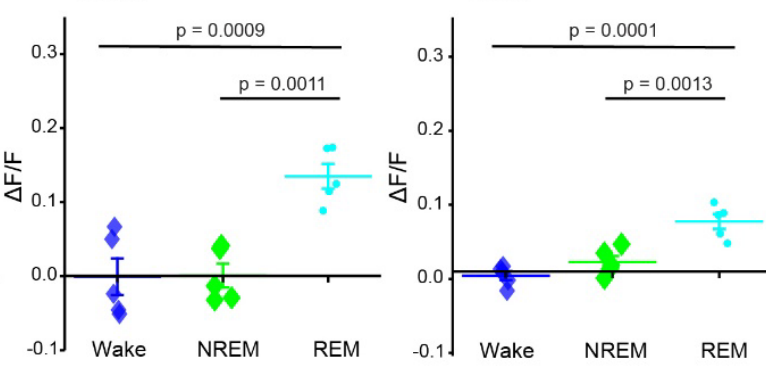
Figure 1. Calcium activity in LPO hypothalamic neurons is highest during REM sleep.

A, schematic representation of optic fibre implantation and AAV-GCaMP6s injection in LPO area of C57BL/6 mice. B, immunohistochemistry staining to show optic fibre track and viral vector expression in LPO, using green fluorescent protein (GFP, in green) antisera and 4',6diamidino-2-phenylindole (DAPI, in blue). Scale bars left $1 \mathrm{~mm}$, right $200 \mu \mathrm{m}$. C, example of photometry recording from LPO neurons aligned to EEG and EMG data. From the top: stage, delta power, EMG, EEG and GCaMP6s signal. The dotted red square indicates the trace's segment expanded below. D, photometry recordings across state transitions normalized as $\Delta \mathrm{F} / \mathrm{F}$ data points. For the transitions to be considered, animals had to be in the behavioural state before and after transitions for at least 30 s each. E, left and centre panels, scaled mean of GCaMP6s signal plotted against EMG (left) and delta power (right); right panel, quantification of LPO calcium activity as $\Delta F / F$ by behavioural state $(n=8$ mice, $F=4.473, P=$ 0241). F, screening of LPO neuronal populations for calcium activity shown as $\Delta F / F$ using gene-specific Cre mouse lines and injection of $A A V$-flex-GCaMP6s. From the left: Vgat-Cre, ( $n=5$ mice $, \mathrm{F}=16.87, P=0.0003)$, Vglut2-Cre $(n=5$ mice, $\mathrm{F}=26.94, P<0.0001)$, Nos1-Cre ( $n=5$ mice, $\mathrm{F}=15.82, P=0.0004)$ and Galanin-Cre $(n=5$ mice, $\mathrm{F}=21.55, P=0.0001)$. In $D, E$ and $F$ data are represented as means \pm SEM. In $E$ and $F$, significance was calculated using one-way ANOVA followed by Tukey's post-hoc test was used. P values showed in these plots are obtained from multiple comparisons analysis and corrected by Tukey's post-hoc test. 
bioRxiv preprint doi: https://doi.org/10.1101/2020.10.19.345728; this version posted October 20, 2020. The copyright holder for this preprint (which was not certified by peer review) is the author/funder, who has granted bioRxiv a license to display the preprint in perpetuity. It is made available under aCC-BY-NC 4.0 International license.

A

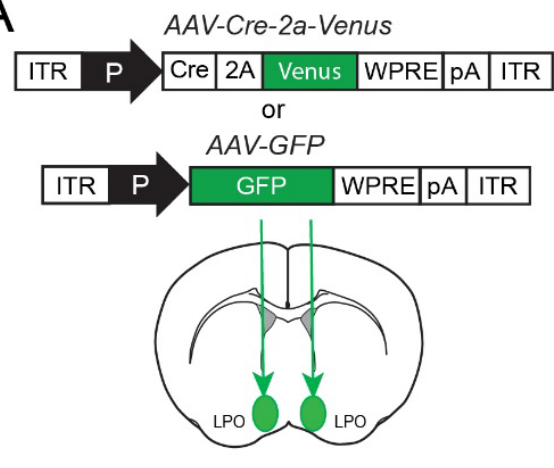

C
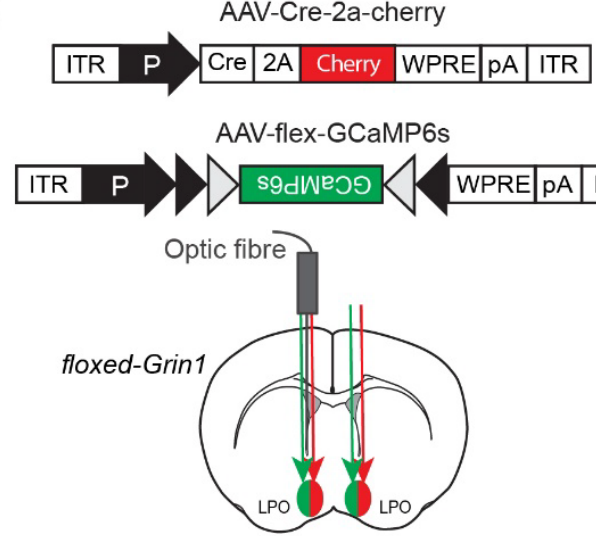
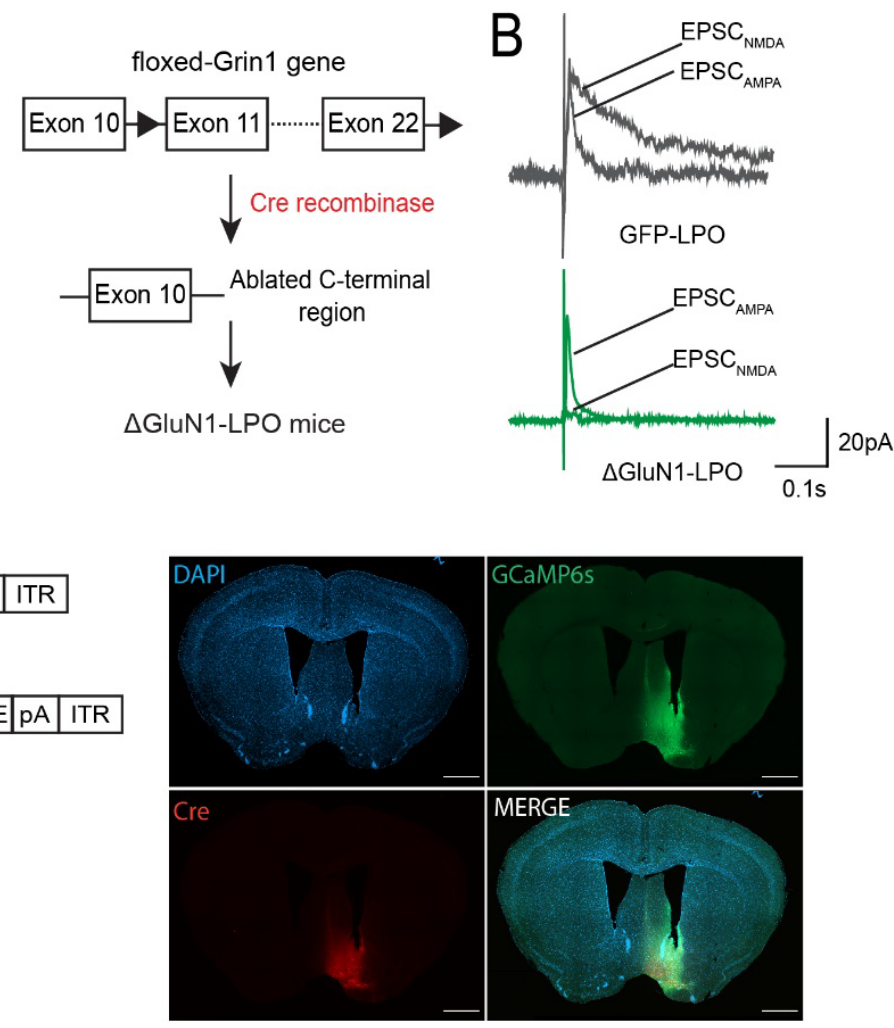

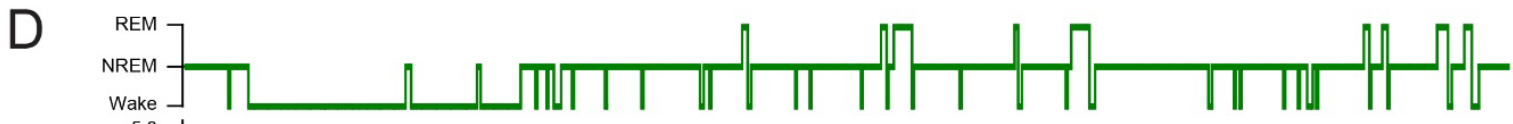
$5.0-$

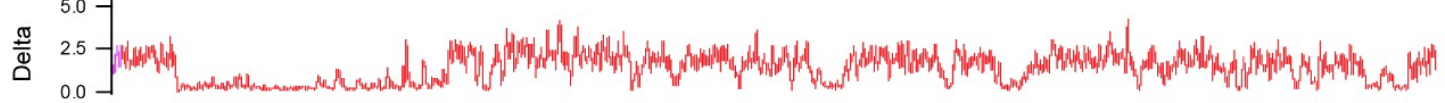

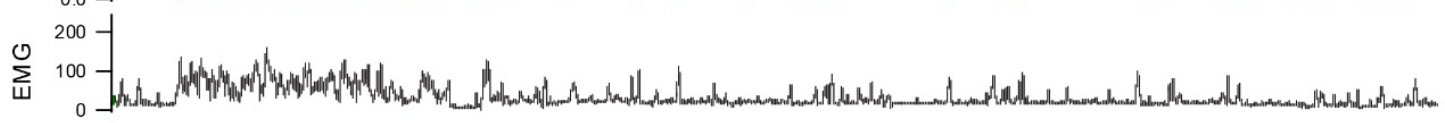

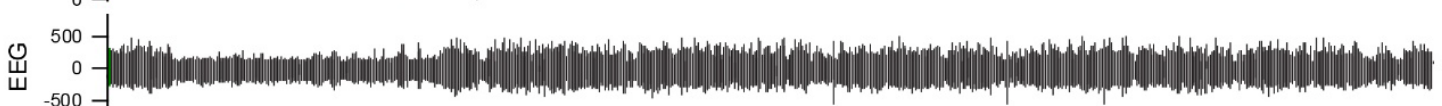

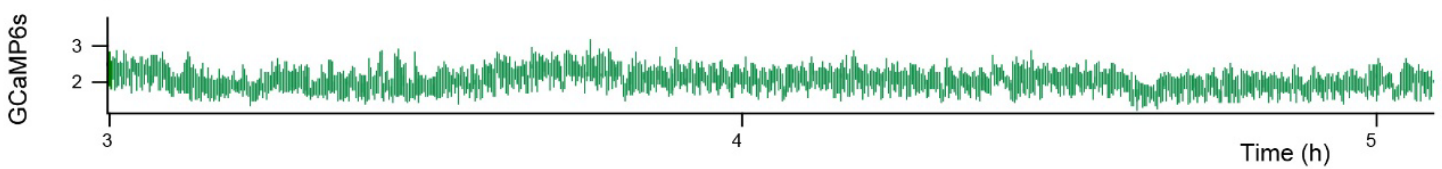
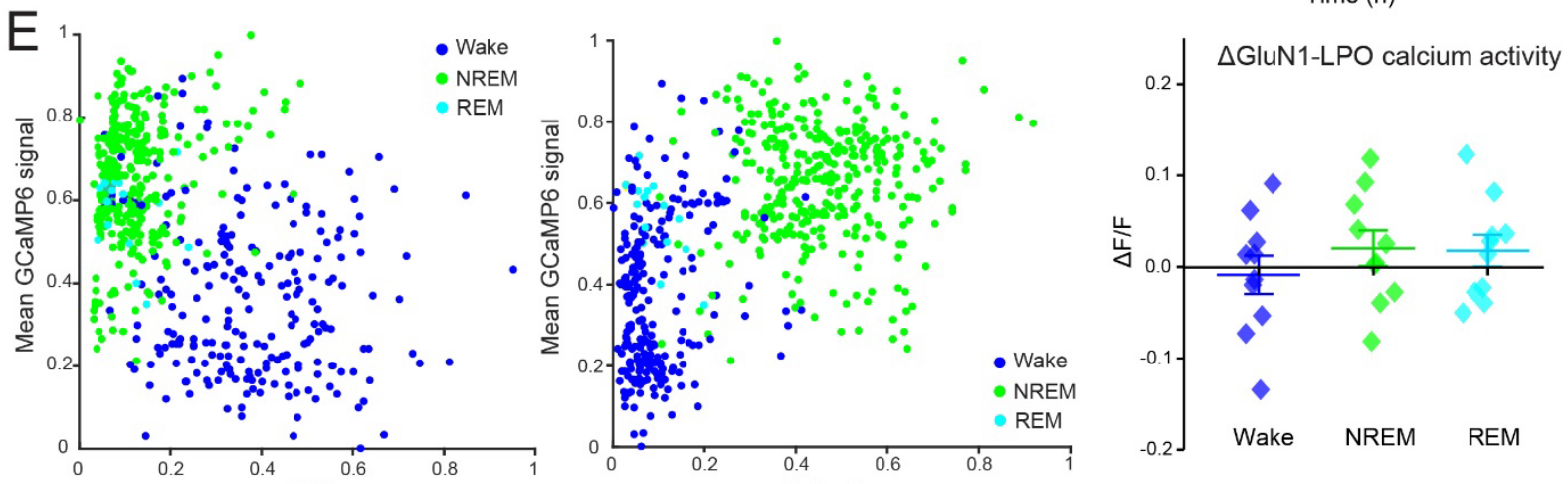
Figure 2. Calcium activity in LPO hypothalamic neurons requires NMDA receptors.

A, generation of $\triangle$ GluN1-LPO and GFP-LPO animals by bilateral injection in LPO of AAV-Cre$2 A-V e n u s$ and AAV-GFP respectively. B, evoked spontaneous post-synaptic currents (EPSCs) in LPO neurons to show NMDA and AMPA receptors currents in GFP-LPO animals (top) and the deletion of NMDA receptor currents in $\triangle$ GluN1-LPO cells (bottom). C, floxedGrin1 animals were bilaterally co-injected in LPO with AAV-Cre-2a-cherry and AAV-flexGCaMP6s viral vectors to record calcium activity only from neurons lacking the NMDA receptors. An optic fibre was also implanted unilaterally for these recordings. On the right, immunohistochemistry showing from left to right: DAPI (blue) and AAV-flex GCaMP6s transgene (green) on the first row, Cre recombinase (red) and merge on the second row. Scale bars represent $1 \mathrm{~mm}$. D, example of a photometry recording aligned to EEG and EMG in a $\triangle$ GluN1-LPO mouse. From the top: vigilance state, delta power, EMG, EEG and GCaMP6s signal. E left and centre panels, scaled mean of GCaMP6s signal plotted against EMG (left) and delta power (centre); right panel, quantification of $\Delta$ GluN1-LPO calcium activity normalized as $\Delta \mathrm{F} / \mathrm{F}$ during behavioural states. One-way ANOVA followed by Tukey's posthoc test $(\mathrm{F}=0.6917, P=5.094) . \Delta \mathrm{GluN1}-\mathrm{LPO}, n=5$. Data in $\mathrm{E}$ (right panel) are represented as mean \pm SEM. 
bioRxiv preprint doi: https://doi.org/10.1101/2020.10.19.345728; this version posted October 20, 2020. The copyright holder for this preprint (which was not certified by peer review) is the author/funder, who has granted bioRxiv a license to display the preprint in perpetuity. It is made available under aCC-BY-NC 4.0 International license.

A

B AAV-Cre-2a-Venus
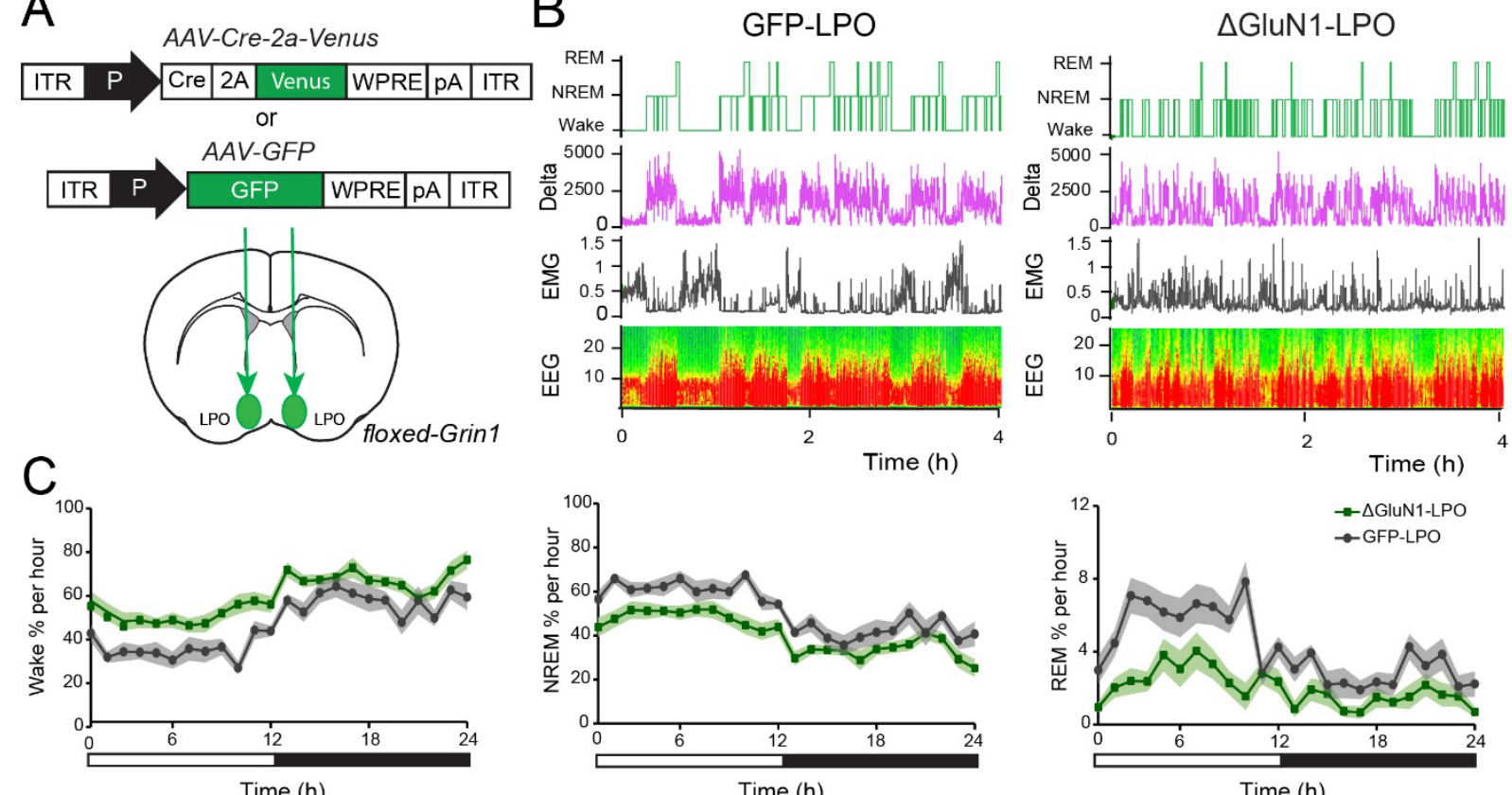

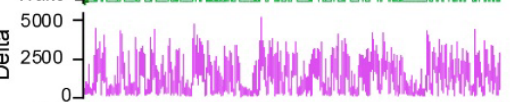

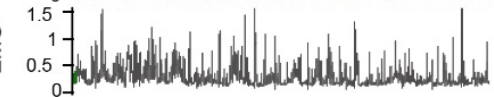

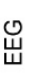
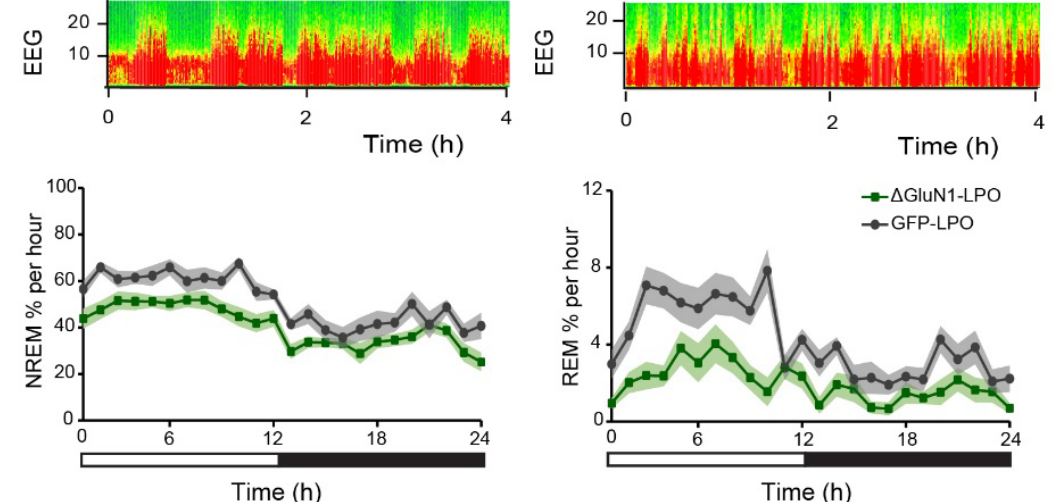

D
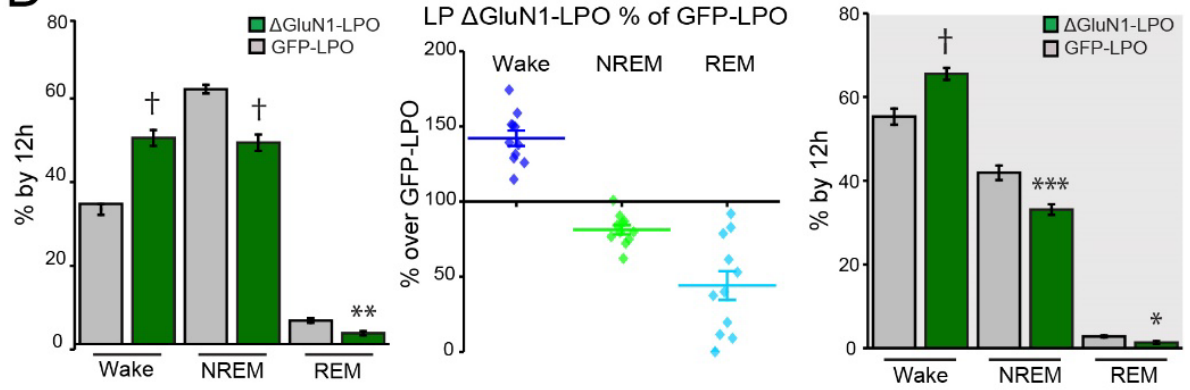

DP $\triangle$ GluN1-LPO \% of GFP-LPO

$E$

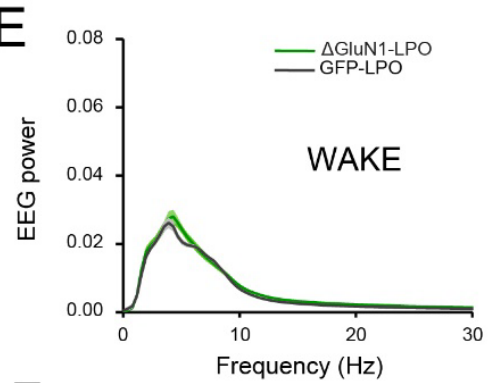

$\mathrm{F}$

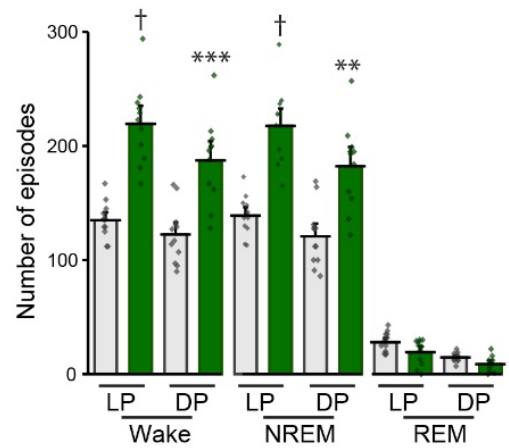

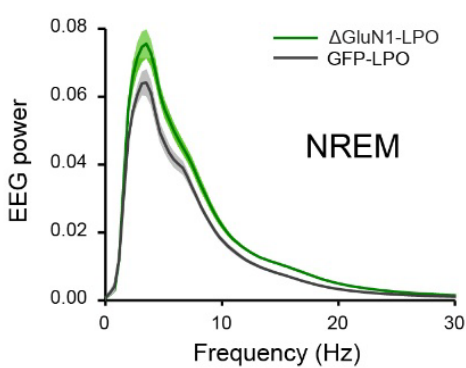

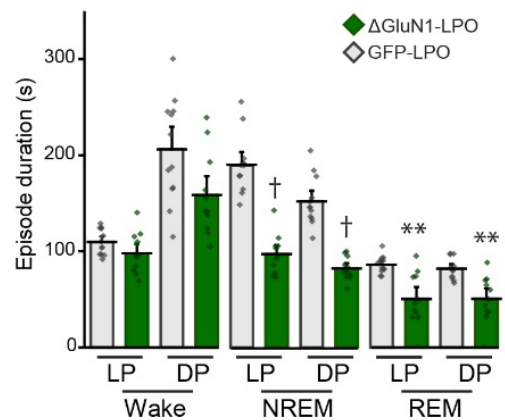

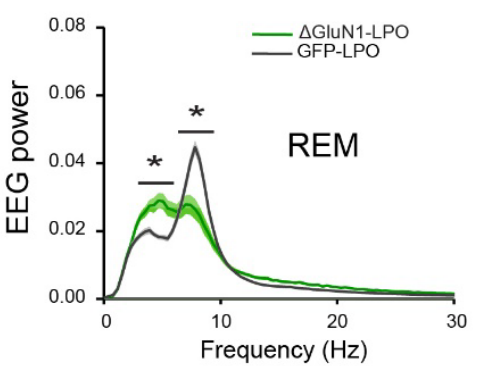

12h LP $\Delta$ GluN1-LPO

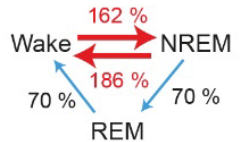

12h DP $\Delta$ GluN1-LPO

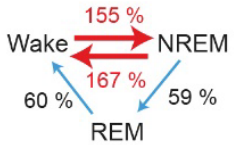




\section{Figure 3. Deletion of NMDA receptors in LPO hypothalamus reduces NREM and REM}

\section{sleep time and produces sleep-wake fragmentation.}

A, bilateral $A A V-C r e-V e n u s$ and $A A V-G F P$ virus injections into LPO of floxed-Grin1 mice to generate $\triangle$ GluN1-LPO and GFP-LPO control animals respectively. B, example of baseline recordings from GFP-LPO (left) and $\triangle$ GluN1-LPO (right) animals. From the top, hypnogram, delta power, EMG, and EEG represented as a somnogram and as a trace. C, 24-hour baseline states distribution as percentage of $1 \mathrm{~h}$ of wake (left), NREM (centre) and REM sleep (right) during light $(0-12 h)$ and dark (12-24h) period. 2-way repeated measures (RM) ANOVA followed by Sidak's post-hoc test, using "time" and "virus" as factors. Wake, "time": F (8.612, $180.9)=14.01, P<0.0001$. NREM, "time": $F(8.972,188.4)=12.67, P<0.0001$; "virus": $F(1$, $21)=41.26, P<0.0001$. REM, "time": $F(9.057,190.2)=8.307, P<0.0001$; "virus": $F(1,21)=$ 18.06, $P=0.0004$. D $1^{\text {st }}$ and $3^{\text {rd }}$ panels, quantification of each behavioural state as percentage over 12 hours of light ( $1^{\text {st }}$ panel) and dark period ( $3^{\text {rd }}$ panel). 2-way ANOVA followed by Sidak's post-hoc test using "state" and "virus" as factors. LP, "state": $F(2,63)=795.5, P<0.0001$; "virus": $F(1,63)=0.0002798, P=0.9867$. DP, "state": $F(2,63)=956.6, P<0.0001$; "virus": $F$ $(1,63)=1.230 \mathrm{e}-005, \mathrm{P}=0.9972 ; 2^{\text {nd }}$ and $4^{\text {th }}$ panels, wake, NREM and REM sleep amounts in $\triangle$ GluN1-LPO mice represented as percentage of GFP-LPO mice amounts during the light $\left(2^{\text {nd }}\right.$ panel) and dark ( $4^{\text {th }}$ panel) periods. E, EEG power spectrum for wake (left), NREM (centre) and REM sleep (right) normalized over total EEG power. 2-way ANOVA followed by Sidak's post-hoc test using "frequency" and "virus" as factors. Wake "frequency": F $(89,1800)=745.9$, $P<0.0001$; "virus": $F(1,1800)=9.142 e-009, P>0.9999$. NREM "frequency": $F(89,1800)=$

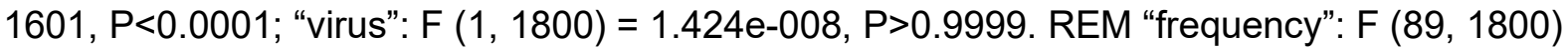
$=399.3, \mathrm{P}<0.0001$; "virus": $\mathrm{F}(1,1800)=4.176 \mathrm{e}-009, \mathrm{P}>0.9999 . \mathrm{F}$ left panel, episode number for $24 \mathrm{~h}$ BL recordings divided by light (LP) and dark period (DP) and behavioural states. 2Way ANOVA followed by Sidak's post-hoc test using "state" and "virus" as factors ("state": F $(5,126)=232.1, P<0.0001$; "virus": $F(1,126)=122.4, P<0.0001)$; centre panel, episode mean duration for each behavioural state during light and dark period. 2-Way ANOVA followed by 
Sidak's post-hoc test using "state" and "virus" as factors ("state": $F(5,126)=60.36, P<0.0001$;

"virus": $F(1,126)=105.1, P<0.0001)$; right panel, $\Delta$ GluN1-LPO mice vigilance state transitions during light (top) and dark (bottom) period represented as percentage over GFPLPO transitions. $\triangle$ GLUN1-LPO, $n=11$; GFP-LPO, $n=12$. In $\mathrm{C}, \mathrm{D}, \mathrm{E}$ and $\mathrm{F}$ data are represented as mean \pm SEM. ${ }^{*} P<0.05,{ }^{* *} P<0.005,{ }^{* *} P<0.0005, \uparrow P<0.00005$ from multiple comparisons analysis corrected by Sidak's (D, E and F) post-hoc test. 

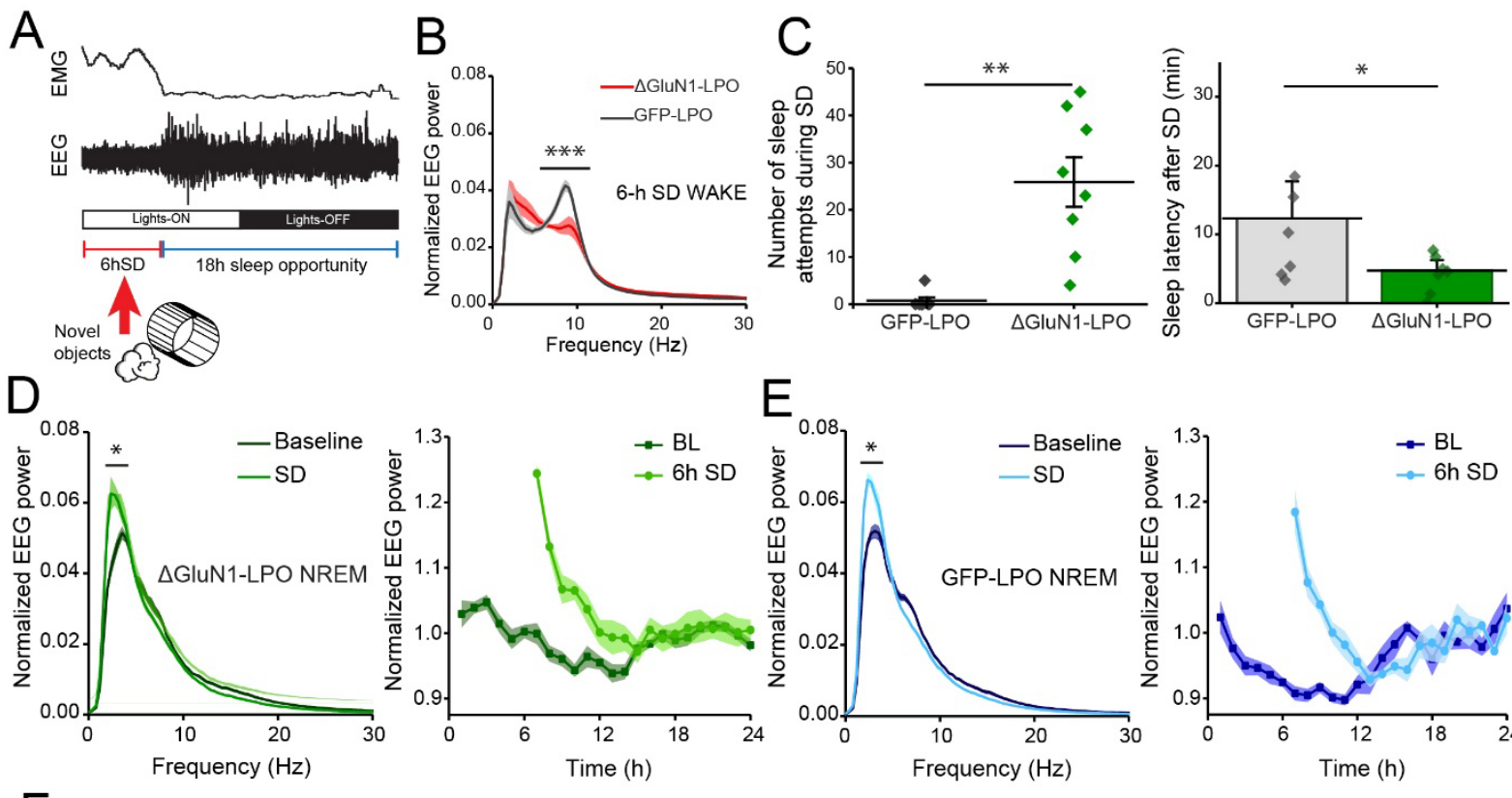

\section{$\mathrm{F}$}
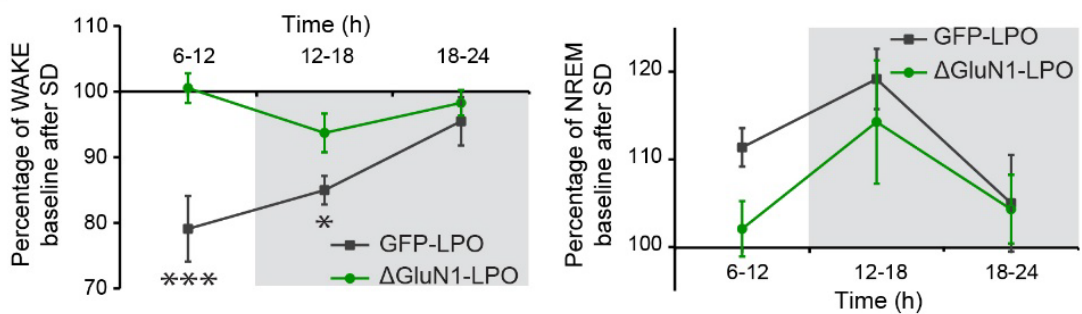

$\Delta$ GluN1-LPO after 6h SD
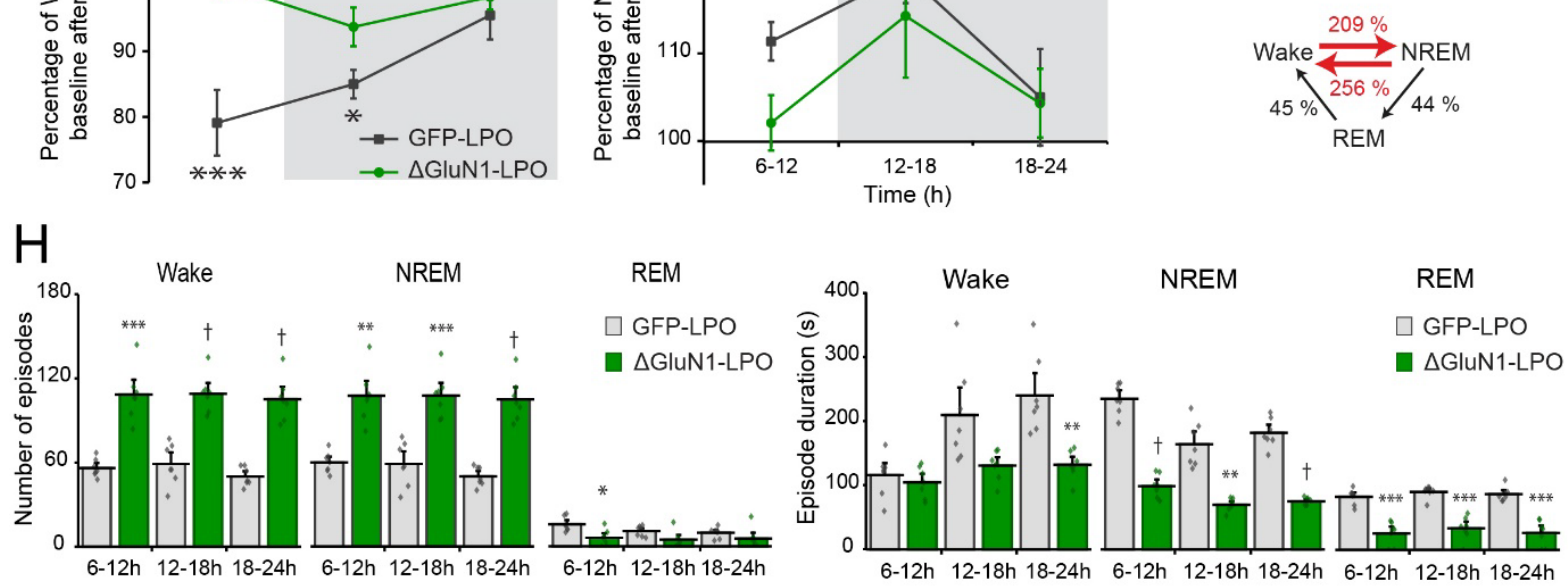
Figure 4. Deletion of the NMDA receptor in LPO does not affect sleep homeostasis and sleep-wake fragmentation still persists in the recovery sleep following sleep deprivation.

A, representation of $6 \mathrm{~h}$ SD protocol starting when lights turn ON, using novel objects to keep the animals awake. For the remaining $18 \mathrm{~h}$ animals are left undisturbed. B, wake EEG power spectrum during 6h SD. 2-Way ANOVA followed by Sidak's post-hoc test using "frequency" and "virus" as factors ("frequency": $F(89,1080)=125.1, P<0.0001$; "virus": $F(1,1080)=$ 4.318e-010, P>0.9999). C, number of sleep attempts during the $6 \mathrm{~h}$ of SD (left) and latency to fall asleep (right) after SD, considering the first NREM bout as at least 30s long. Mann-Whitney test was used for sleep attempts $(P=0.0006)$ and unpaired Student's $t$ test for latency $(P=$ 0.049). D and E left panels, NREM EEG power spectrum during $1 \mathrm{~h}$ following $6 \mathrm{~h}$ sleep deprivation (SD) compared with same circadian time during baseline recordings in $\Delta$ GluN1LPO (D) and in GFP-LPO (E) animals. 2-Way ANOVA followed by Sidak's post-hoc test using "frequency" and "virus" as factors. $\Delta$ GluN1-LPO "frequency": $F(89,1080)=653.1, P<0.0001$; "virus": $F(1,1080)=8.999 e-009$, P>0.9999. GFP-LPO "frequency": $F(89,1080)=963.5$, $\mathrm{P}<0.0001$; "virus": $\mathrm{F}(1,1080)=7.930 \mathrm{e}-009, \mathrm{P}>0.9999$; right panels, NREM EEG delta power calculated for every hour during baseline recordings and after 6h SD in $\triangle$ GluN1-LPO and GFP-LPO animals. The EEG power was normalized over the total power during each hour. $\mathbf{F}$, percentage of wake (left) and NREM sleep amounts (right) in $\triangle$ GluN1-LPO and GFP-LPO mice over their own baseline after 6h SD. 2-Way ANOVA followed by Sidak's post-hoc test using "time" and "virus" as factors (Wake "time": $F(1.564,18.77)=5.867, P=0.0151$; "virus": $F(1,12)=10.69, P=0.0067$. NREM “time": $F(1.479,17.74)=3.180, P=0.0782 ;$ "virus": $F(1$, $12)=2.906, P=0.1140) . G, \Delta G l u N 1-L P O$ transitions in the $18 \mathrm{~h}$ following $6 \mathrm{~h}$ SD presented as percentage of GFP-LPO mice transitions. $\mathbf{H}$ left panels, episode number calculated over $6 \mathrm{~h}$ following SD for wake (left), NREM (centre) and REM sleep (right). 2-Way RM ANOVA followed by Sidak's post-hoc test using "time" and "virus" as factors. Wake, "virus": F $(1,12)=$ 79.90, $\mathrm{P}<$ 0.0001; "time": $\mathrm{F}(1.852,22.23)=1.786, \mathrm{P}=0.1924$. NREM, "virus": $\mathrm{F}(1,12)=$ 
64.85, $P<0.0001$, "time": $F(1.937,23.24)=1.780, P=0.1916$. REM, "virus": $F(1,12)=6.25$, $\mathrm{P}=0.0279$, "time": $\mathrm{F}(1.905,22.87)=6.702, \mathrm{P}=0.0056$. Right panels, episode mean duration calculated by 6h following SD for wake (left), NREM (centre) and REM sleep (right). 2-Way RM ANOVA followed by Sidak's post-hoc test using "time" and "virus" as factors. Wake, "virus": $F(1,12)=17.30, P=0.0013$, "time": $F(1.885,22.62)=13.10, P=0.0002$. NREM, "virus": $F(1$, $12)=202.5, P<0.0001$, "time": $F(1.676,20.12)=27.04, P<0.0001 . R E M$, "virus": $F(1,12)$ $=63.84, \mathrm{P}<0.0001$, "time": $\mathrm{F}(1.853,22.24)=2.672, \mathrm{P}=0.0946$. GFP-LPO, $n=7 ; \Delta \mathrm{GluN1}-$ LPO, $n=7$. Data in all panels $\mathrm{B}, \mathrm{C}, \mathrm{D}, \mathrm{E}, \mathrm{F}$ and $\mathrm{H}$ are represented as means $\pm \mathrm{SEM}$. ${ }^{*} P<0.05$, ${ }^{* *} P<0.005,{ }^{* * *} P<0.0005,1 P<0.00005$ from multiple comparisons analysis using Sidak's post-hoc correction. 
A BL Vs Dex states distribution
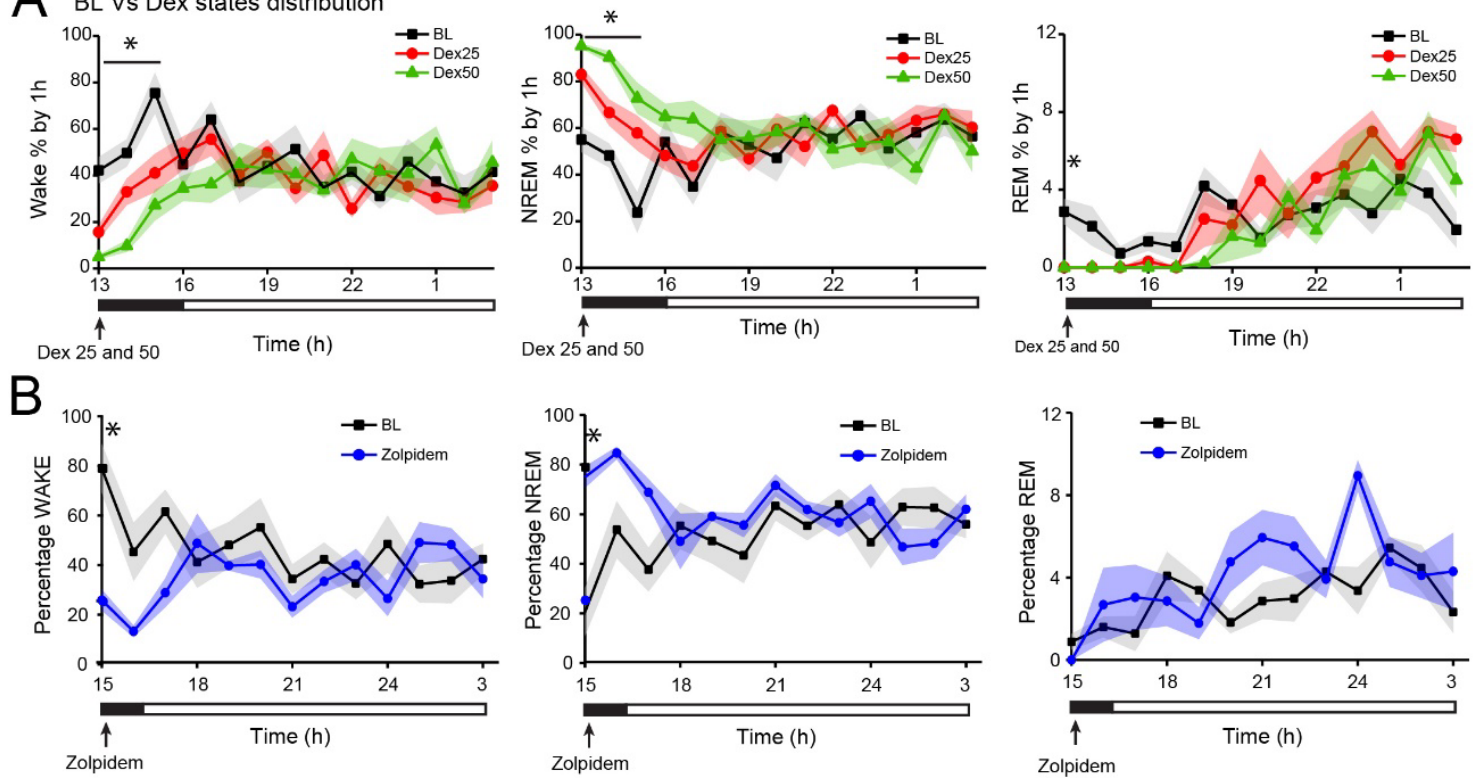

C
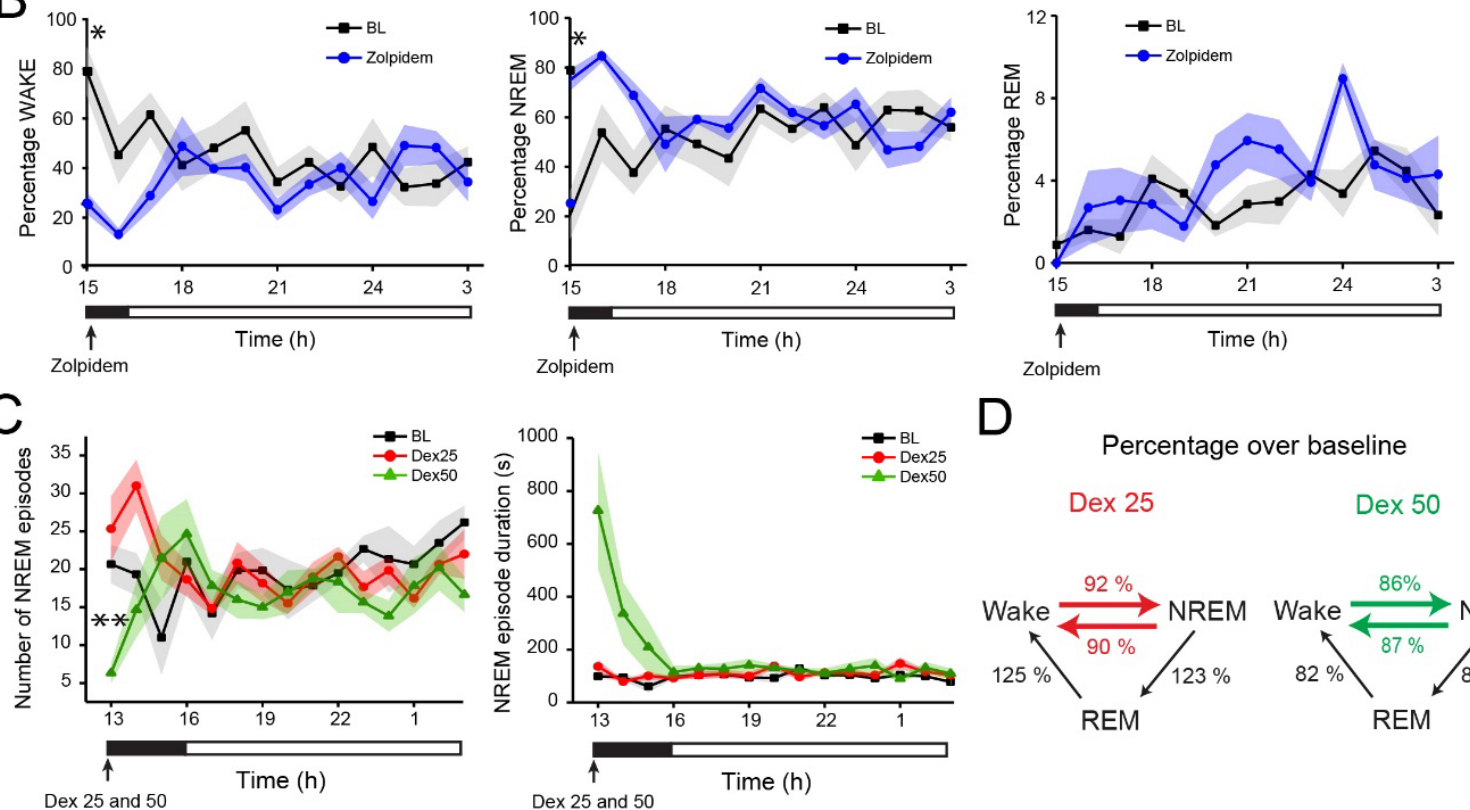

D Percentage over baseline

Dex 25

Dex 50

E
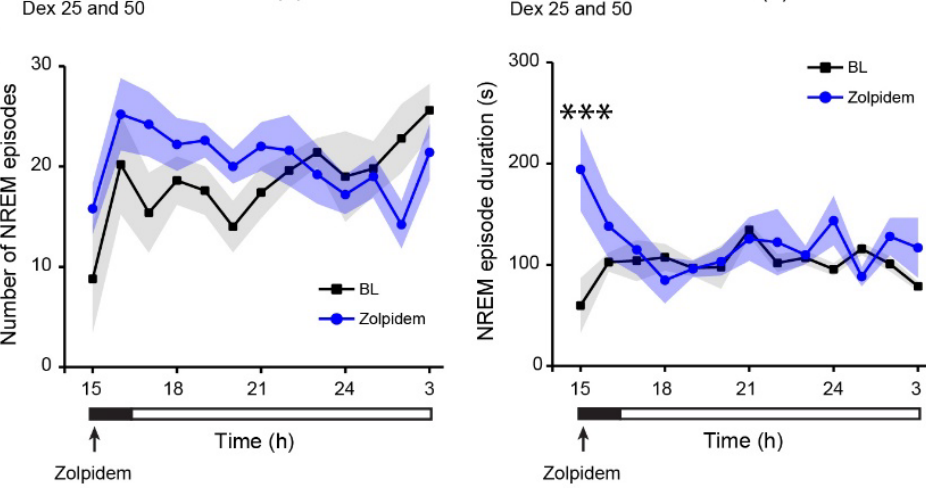

$\mathrm{F}$

Percentage over baseline

Zolpidem

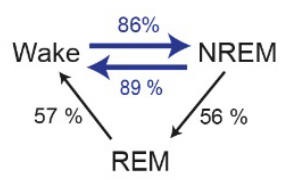


Figure 5. Dexmedetomidine and zolpidem both increase sleep time and dexmedetomidine reduces sleep fragmentation in mice lacking NMDA receptors in LPO.

A, baseline states distribution as percentage of $1 \mathrm{~h}$ in wake (left), NREM (centre) and REM sleep (right) compared with the distribution after injection of Dex $25 \mu \mathrm{g} / \mathrm{Kg}$ (red) and Dex $50 \mu \mathrm{g} / \mathrm{Kg}$ (green) at 13:00. 2-Way RM ANOVA followed by Tukey's post-hoc test using "time" and "dose" as factors. For wake "time": $F(6.834,102.5)=3.244, P=0.0040$; "dose": $F(2,15)$ $=8.067, P=0.0042$. For NREM “time": $F(6.768,101.5)=3.669, P=0.0016$; "dose": $F(2,15)=$ 7.578, $P=0.0053$. For REM "time": $F(5.394,80.92)=13.74, P<0.0001$; "dose": $F(2,15)=$ 1.808, $P=0.1980$ ). B, distribution by hour of wake (left), NREM (centre) and REM sleep (right) following injection of zolpidem 5mg/kg at 15:00. 2-Way RM ANOVA followed by Tukey's posthoc test using "time" and "dose" as factors. For wake, "time": F $(4.342,34.73)=1.596$, $P=0.1937 ;$ "dose": $F(1,8)=6.412, P=0.0351$. For NREM sleep, "time": $F(4.377,35.01)=$ 1.568, $P=0.2006$; "dose": $F(1,8)=6.006, P=0.0399$. For REM sleep, "time": $F(4.315,34.52)$ $=4.355, \mathrm{P}=0.0050$; "dose": $\mathrm{F}(1,8)=2.192, \mathrm{P}=0.1770$. $\mathrm{C}$, number of NREM episodes (left) and NREM episode mean duration (right) comparing baseline to dexmedetomidine $(25 \mu \mathrm{g} / \mathrm{kg}$ and $50 \mu \mathrm{g} / \mathrm{kg}$ ) sleep recordings. 2-Way RM ANOVA followed by Tukey's post-hoc test using "time" and "dose" as factors (left panel: "time": $F(6.165,92.48)=1.850, P=0.1198$; "dose": $F$ $(2,15)=1.728, P=0.3142$; right panel: "time": $F(1.266,18.99)=5.741, P=0.02098$; "dose": $F$ $(2,15)=6.516, P=0.0092)$. D, number of transitions during the "lights on" period after injection of dexmedetomidine $25 \mu \mathrm{g} / \mathrm{kg}$ (left) and $50 \mu \mathrm{g} / \mathrm{kg}$ (right), represented as percentage over the baseline recordings at the same circadian time. E, NREM episode number (left) and mean duration (right) comparing baseline to zolpidem $(5 \mathrm{mg} / \mathrm{kg}$ ) sleep recordings. 2-Way RM ANOVA followed by Tukey's post-hoc test using "time" and "dose" as factors (left panel: "time": $F(5.530,44.24)=2.142, P=0.0720$; "dose": $F(1,8)=0.6910, P=0.4299$; right panel: "time": $F(12,96)=0.7856, P=0.6639 ;$ “dose": $F(1,8)=3.234, P=0.1098) . F$, number of transitions during the light period after injection of zolpidem represented as percentage over the baseline 
bioRxiv preprint doi: https://doi.org/10.1101/2020 10.19.345728; this version posted October 20, 2020. The copyright holder for this preprint (which was not certified by peer review) is the author/funder, who has granted bioRxiv a license to display the preprint in perpetuity. It is made available under aCC-BY-NC 4.0 International license.

recordings at the same circadian time. For all panels, $\Delta$ GluN1-LPO, $n=6$. Data in $A, B, C$ and E are represented as mean \pm SEM. ${ }^{*} P<0.05,{ }^{* *} P<0.005$ from multiple comparisons analysis using Tukey's post-hoc correction. 
bioRxiv preprint doi: https://doi.org/10.1101/2020.10.19.345728; this version posted October 20, 2020. The copyright holder for this preprint (which was not certified by peer review) is the author/funder, who has granted bioRxiv a license to display the preprint in perpetuity. It is made available under aCC-BY-NC 4.0 International license.

A

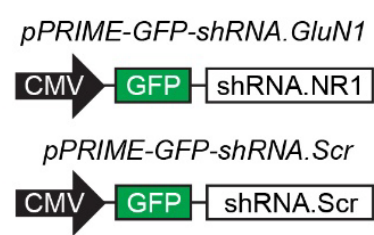

Co-transfection into HEK cells pcDNA3.1-GluN1-cherry

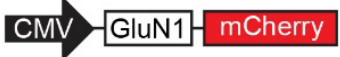

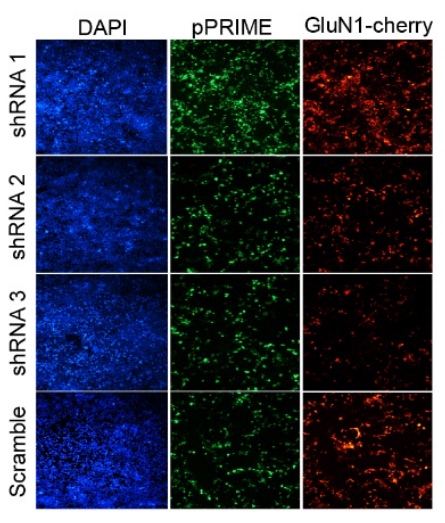

D

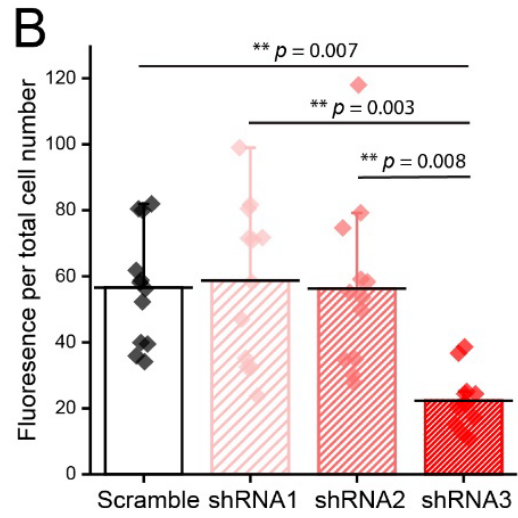

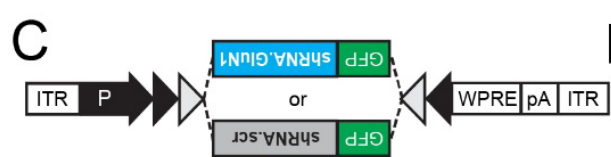
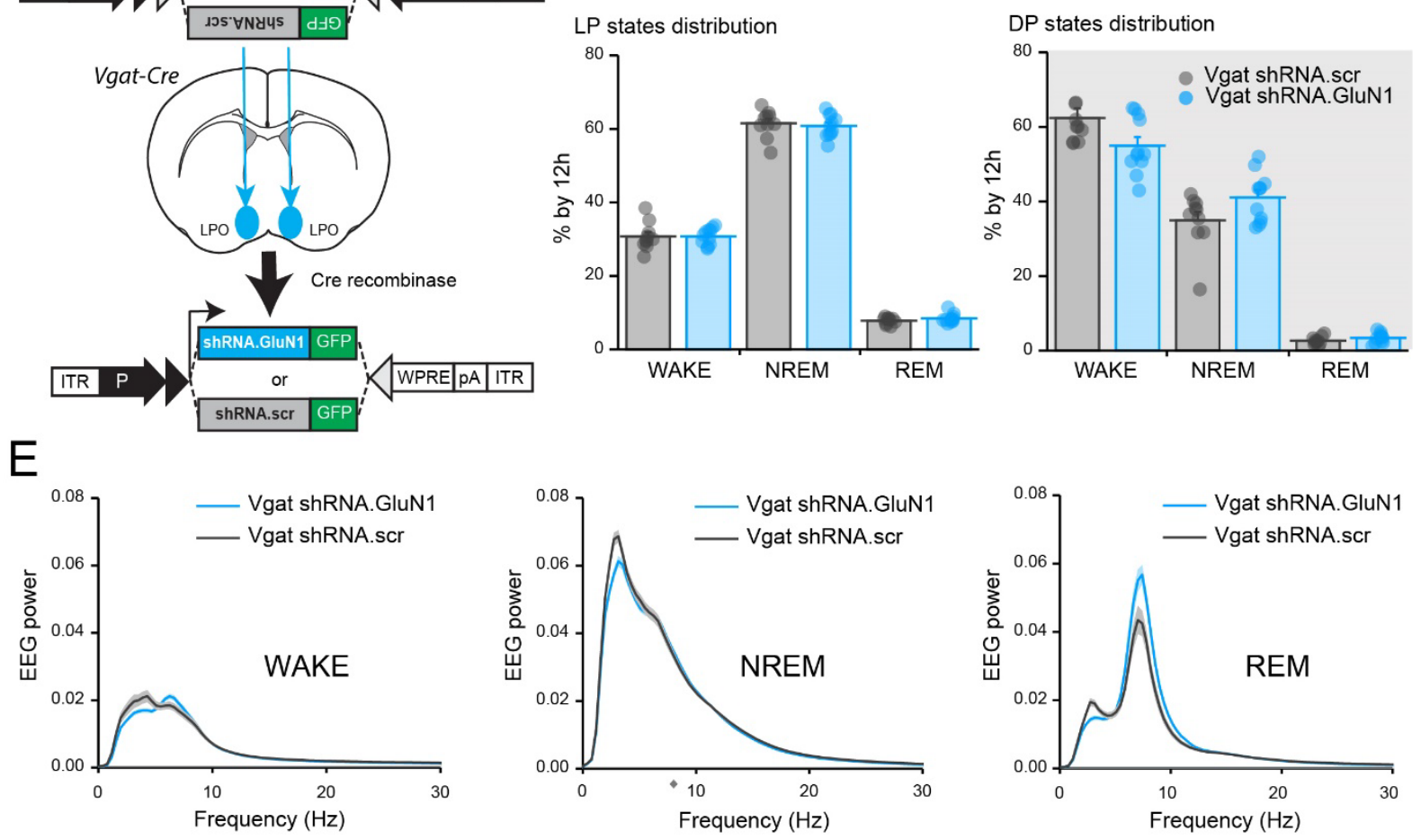

F BL episodes number
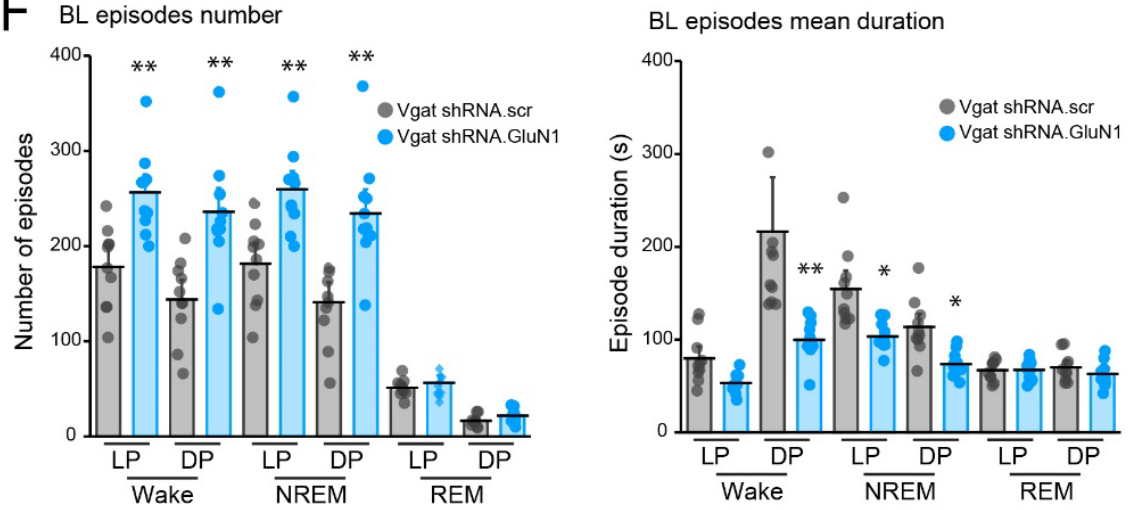

Vgat shRNA.GluN1

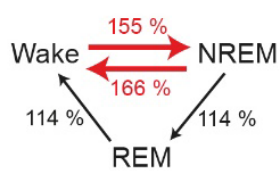


Figure 6. NMDA receptor GluN1 knock-down from GABA neurons in the LPO hypothalamus causes sleep-wake fragmentation but not sleep loss.

A, DNA constructs used to test shRNA-GluN1 efficiency (left) and fluorescent images (right) of transfected HEK293 cells showing DAPI (left column, in blue), GFP reporter for expression of shRNA-GluN1 and shRNA-scramble pPRIME vectors (central column, in green), and mCherry reporter expression which indicates expression of the plasmid carrying the GluN1 sequence (right column, in red). B, quantification of mCherry fluorescence per total cell number after transfection of HEK293 cells with plasmids expressing the shRNA-GluN1 or the control scramble shRNA. $N=10$, one-way ANOVA followed by Tukey's post-hoc test for multiple comparisons ( $\mathrm{F}=9.126$; $P<0.0001)$. C, AAV-flex-shRNA-GluN1 or AAV-flex-shRNAscramble (scr) were bilaterally injected in the LPO area of Vgat-cre animals to generate Vgat shRNA-GluN1 and Vgat-shRNA-scr animals. D, vigilance state distribution represented as \% of $12 \mathrm{~h}$ during light (left) and dark (right) periods for Vgat shRNA-GluN1 and Vgat-shRNA-scr animals. 2-Way ANOVA followed by Sidak's post-hoc test using "state" and "virus" as factors ("state": $F(5,113)=563.6, P<0.0001$; "virus": $F(1,113)=0.02612, P=0.8719) . E, E E G$ power spectrum of wake (left), NREM (centre) and REM (right) sleep during $12 \mathrm{~h}$ light period in VgatshRNA-GluN1 animals normalized over total EEG power. $\mathbf{F}$ left and centre panels, baseline episode number (left) and episode mean duration (centre) comparing Vgat-shRNA-GluN1 with control Vgat shRNA-scr mice. 2-Way ANOVA followed by Sidak's post-hoc test using "state" and "virus" as factors. For episode number, "state": $F(5,114)=109.6, \mathrm{P}<0.0001$; "virus": $\mathrm{F}$ $(1,114)=72.99, P<0.0001$. For mean duration, "state": $F(5,114)=39.01, P<0.0001$; "virus": $F(1,114)=62.05, P<0.0001$; right panel, number of transitions in Vgat shRNA-GluN1 mice represented as percentage over control group during $24 \mathrm{~h}$ baseline recordings. Vgat-shRNGluN1, $n=12$; Vgat-shRNA-scr, $n=11$. In B, D, E and F data are represented as mean \pm SEM. In $\mathrm{F},{ }^{*} P<0.05,{ }^{* *} P<0.005$ from multiple comparison analysis corrected by Sidak's post-hoc test. 


\section{MATERIAL AND METHODS}

\section{Mice}

All experiments were performed in accordance with the United Kingdom Home Office Animal Procedures Act (1986) and were approved by the Imperial College Ethical Review Committee. Wild-type C57BL/6N mice were purchased from Charles River at $7 / 8$ weeks of age. Grin $1^{\text {flox }}$ (also known as NR1 ${ }^{\text {flox }}$ or fNR1) mice (Tsien et al., 1996) were purchased from The Jackson Laboratory (Jack stock number 005246) after kind donation by S. Tonegawa. Vglut2-Cre animals (Vglut2-ires-Cre: S/c17a6 $6^{\text {tm2(cre)Lowl/J) }}$ and Vgat-Cre mice (Vgat-ires-Cre: S/c32a $1^{\text {tm2(cre)Lowl } / J) ~ w e r e ~ k i n d l y ~ p r o v i d e d ~ b y ~ B . B . ~ L o w e l l ~ a n d ~ p u r c h a s e d ~ f r o m ~ T h e ~ J a c k s o n ~}$ Laboratory (JAX stock 016963 and 016962)(Vong et al., 2011). Galanin-Cre mice (Tg(Galcre)KI87Gsat/Mmucd) were generated by GENSAT and kindly deposited at the Mutant Mouse Regional Resource Center, stock No. 031060-UCD, GENSAT- Project (NINDS Contracts N01NS02331 \& HHSN271200723701C to The Rockefeller University, New York) (Schmidt et al., 2013). Nos-Cre animals (Nos1-ires-Cre $\left.e^{t m 1(\mathrm{cre}) M g m j} / J\right)$, were kindly provided by M. G. Myers, and purchased from The Jackson Laboratory (JAX stock 017526) (Leshan et al., 2012).

All mice were housed at a maximum of five mice per cage with food and water ad libitum and maintained under the same conditions $(21 \pm 1 \mathrm{C}$, reversed $12 \mathrm{~h}$ dark/light cycle starting at 4:00 AM). For behavioural experiments, mice were singly housed, and experiments performed during lights-OFF unless otherwise specified, while photometry recordings were performed during lights-ON.

\section{Transgenes and AAVs}

All AAVs (serotype 1/2) were produced in house. The adenovirus helper plasmid $\mathrm{pF} \Delta 6$, the AAV helper plasmids $\mathrm{pH} 21$ (AAV1) and $\mathrm{pRVI}(\mathrm{AAV} 2)$, and the $\mathrm{pAAV}$ transgene plasmids were co-transfected into HEK293 cells and the resulting AAVs collected on heparin columns, as described previously (Klugmann et al., 2005; Yu et al., 2015). Plasmid pAAV-iCre-2AVenus was provided by Thomas Kuner (Abraham et al., 2010). Plasmid pAAV-GFP was a gift 
from John T. Gray (Addgene plasmid 32396). To create pAAV-hsyn-GCaMP6s and the pAAVhsyn-flex-GCaMP6s, the GCaMP6s reading frame from pGP-CMV-GCaMP6s (Addgene plasmid 40753, gift of Douglas Kim) (Chen et al., 2013) was mutated into $p A A V-f l e x-h M 3 D_{q^{-}}$ mCHERRY (Krashes et al., 2011), either removing the flex-M3-cherry component or keeping both sets of loxP sites ( $p A A V$-flex backbone), respectively. For knocking down GluN1 expression cell type-selectively, the pPRIME system (Stegmeier et al., 2005), cloned into AAV transgenes, was used to generate shRNAs - see section ("Generation of shRNAs to target GluN1").

\section{Surgeries}

All surgeries used adult male and female mice, 8-12 weeks old and were performed under deep general anaesthesia with isoflurane (3\% induction/ $2 \%$ maintenance) and under sterile conditions. Before starting the surgery, mice were injected subcutaneously (s.c.) with Buprenorphine (Vetergesic $0.3 \mathrm{mg} / \mathrm{mL}, 1: 20$ dilution in $0.9 \%$ sterile saline solution, final $0.1 \mathrm{mg} / \mathrm{kg}$ ) and Carprofen (Rimadyl $50 \mathrm{mg} / \mathrm{mL}, 1: 50$ dilution in $0.9 \%$ sterile saline solution, final $5 \mathrm{mg} / \mathrm{kg}$ ) and then placed in a stereotaxic frame. Mouse core temperature was constantly checked by rectal probe while respiration rate was regularly checked by eye.

For AAV injections, the virus was injected at a rate of $0.1 \mu \mathrm{L} / \mathrm{min}$ using Hamilton microliter \#701 $10 \mu \mathrm{L}$ syringes and a stainless-steel needle (33-gauge, $15 \mathrm{~mm}$ long). LPO coordinates used for bilateral injection sites were relative to Bregma: $\mathrm{AP},+0.40 ; \mathrm{ML},-/+0.75$, DV was consecutive, injecting half volume at +5.20 and half at +5.15 . A total volume of $0.3 \mu \mathrm{L}$ each side was injected. Control AHA coordinates used for bilateral injections sites were relative to Bregma: $\mathrm{AP},-0.58$; $\mathrm{ML},-/+0.65 ; \mathrm{DV},+5.60$ and +5.50 for consecutive injections. Mice injected with AAVs were allowed 1 month for recovering and for the viral transgenes to adequately express before being fitted with Neurologger 2A devices (see below) and undergoing any experimental procedures. 
For sleep recordings, EEG screw electrodes were chronically implanted on mice skull and EMG wire electrodes (AS634, Coorner Wire) were inserted in the neck extensor muscles. EEG screws were placed on the skull at: $-1.5 \mathrm{~mm}$ midline, $+1.5 \mathrm{~mm}$ Bregma; $-1.5 \mathrm{~mm}$ midline, -2 mm Bregma; +1.5 mm midline, -2 mm Bregma.

For fibre photometry, a monofibre ( $\varnothing 200 \mu \mathrm{m}, 0.37 \mathrm{NA}$, Doric Lenses) was chronically implanted together with EEG and EMG electrodes. The fibre was positioned after AAV injections above the LPO following coordinates relative to Bregma: AP, +0.10; ML, $-0.90, \mathrm{DV}$, $-5.00 \mathrm{~mm}$.

For all surgeries, the wound was sewed around the headstage and the mouse was left recovering in a heat box. All instrumented mice were single housed to avoid lesions to the headstage.

\section{EEG/EMG recordings and analysis}

EEG and EMG traces were recorded using Neurologger 2A devices as described before (Anisimov et al., 2014; Gelegen et al., 2014; Vyssotski et al., 2009), at a sampling rate of 200 $\mathrm{Hz}$. The data obtained from the Neurologger $2 \mathrm{~A}$ were downloaded and visualized using Spike2 Software (Cambridge Electronic Design, Cambridge, UK). The EEG was high pass filtered $(0.5 \mathrm{~Hz},-3 \mathrm{~dB})$ using a digital filter, while EMG was band pass filtered between $5-45 \mathrm{~Hz}$ $(-3 \mathrm{~dB})$. To define the vigilance states of Wake, NREM and REM sleep, delta power (0.5-4.5 $\mathrm{Hz}$ ) and theta ratio (theta power [5-10 Hz]/delta power) were calculated, as well as the EMG integral. Automated sleep scoring was performed using a Spike2 script and the result was manually corrected. For the three vigilance states, amounts percentages were calculate using costume Spike2 scripts. For sleep architecture analysis, costume MATLAB scripts were used. Fast Fourier transformation (512 points) was used to calculate EEG power spectra.

\section{Sleep deprivation protocol and drug testing}

Mice were fitted with Neurologger $2 \mathrm{~A}$ devices and the $24 \mathrm{~h}$ sleep-wake baseline $(\mathrm{BL})$ was recorded. After BL, mice with Neurologger $2 \mathrm{~A}$ devices were sleep deprived from the light 
period onset (4:00pm) for 6 hours, introducing novel objects in their home cage (Tobler et al., 1997). To make the procedure minimally stressful, mice were never touched, apart from when changing cages. Sleep recordings were stopped at the end of the dark period of the following day $(4: 00 p m)$.

Dexmedetomidine injections were prepared from stock solution of $0.5 \mathrm{mg} / \mathrm{mL}$ (Dexdomitor), diluted in sterile saline before injections. Mice were i.p. injected with the dose of 25 or $50 \mu \mathrm{g} / \mathrm{kg}$ at 1:00 pm (lights-OFF) to record sleep and fragmentation phenotype. Zolpidem injections were prepared by dissolving zolpidem tartrate powder (Sigma-Aldrich) in sterile saline. Mice were injected i.p. with $5 \mathrm{mg} / \mathrm{kg}$ of solution at 3:00 pm (light-OFF) and their EEG/EMG traces recorded for at least 24 hours.

\section{Histology and immunostaining}

Animals were perfused transcardially with $20 \mathrm{~mL}$ of cold $1 \times$ PBS at a rate on $4 \mathrm{~mL} / \mathrm{min}$, followed by $20 \mathrm{~mL} 4 \%$ paraformaldehyde (PFA, 4mL/min) in 1x PBS. Brains were dissected and post-fixed in 4\% PFA overnight, and then transferred in $30 \%$ sucrose. After 3 days in sucrose, brains were cut in 35- $\mu \mathrm{m}$ coronal slice using a microtome (Leica). For staining, slices were transferred in an epitope retrieval solution $(0.05 \%$ Tween-20, $10 \mathrm{mM}$ sodium citrate buffer, and $\mathrm{pH} 6.0$ ) for $20 \mathrm{~min}$ at $82^{\circ} \mathrm{C}$, then left at room temperature (RT) for $15 \mathrm{~min}$ before being washed. After 3 washes of 10min in 1x PBS, brain slices were blocked in $0.2 \%$ Triton $^{\mathrm{TM}}$ $\mathrm{x}-100$ (Sigma-Aldrich), 20\% Normal Goat Serum (NGS, Vector Laboratories) in 1x PBS for 1h at RT, shaking. Primary antibody staining was then performed overnight at $4^{\circ} \mathrm{C}$ shaking in $0.2 \%$ Triton, $2 \%$ NGS in $1 \times$ PBS. In case of double staining, both primary antibodies were added in the solution unless cross-reactivity was previously observed. The following day, slices were washed 3 times in 1x PBS for 10 minutes and then secondary antibody solution was applied for $1 \mathrm{~h}$ and $30 \mathrm{~min}$ in $0.2 \%$ Triton, $2 \%$ NGS in $1 \times$ PBS, at RT shacking. If double staining was required, washes and another secondary antibody incubation were carried out. For anti-IBA1 staining, donkey normal serum was used instead that NGS with same dilutions. After secondary antibodies incubations, slices were washed again for 3 times for $10 \mathrm{~min}$, RT 
in 1x PBS shacking and DAPI staining (1:5000 in PBS, Hoechst 33342, Life Technologies) was then performed for a maximum of $10 \mathrm{~min}$. After at least 1 wash in $1 \mathrm{x}$ PBS, slices were ready to be mounted. For mounting, microscope slides (Superfrost PLUS, Thermo Scientific), mounting media ProLong ${ }^{\mathrm{TM}}$ Gold Antifade Reagent (Invitrogen) and glass cover slides (24 X $50 \mathrm{~mm}$, VWR Internartional) were used. Primary antibodies: rabbit anti-GFP (Invitrogen, A6455, 1:1000), chicken anti-GFP (Abcam, ab13970, 1:1000), rabbit anti-GFAP (Dako, Z0334, 1:500), goat anti-IBA-1 (Abcam, ab5076, 1:500), rat anti-mCherry (Invitrogen, M11217, 1:1000). Secondary antibodies (all from Invitrogen): Alexa Fluor-488 goat anti-Chicken (A11039, 1:500), Alexa Fluor-488 goat anti-rabbit (A11008, 1:500), Alexa Fluor-594 goat anti rabbit (A11072, 1:500) and Alexa Fluor-594 donkey anti-goat (A11058, 1:500), Alexa Fluor568 goat anti-rat (A11077, 1:500).

\section{Acute slice preparation and electrophysiology recordings}

Mice were euthanized by cervical dislocation and subsequent decapitation. The brain was rapidly retrieved to be sliced and placed into cold oxygenated N-Methyl-D-glucamine (NMDG) solution (in mM: NMDG 93, $\mathrm{HCl} 93, \mathrm{KCl} 2.5, \mathrm{NaH} 2 \mathrm{PO} 4$ 1.2, NaHCO3 30, HEPES 20, glucose 25 , sodium ascorbate 5 , Thiourea 2 , sodium pyruvate $3, \mathrm{MgSO} 410, \mathrm{CaCl} 2$ 0.5). Parahorizontal slices (thickness $300 \mu \mathrm{m}$ ) encompassing the LPO area were obtained using a vibrotome (Vibrating Microtome 7000smz-2; Campden Instruments LTD, UK). Slices were incubated for $15 \mathrm{~min}$ in NMDG solution at $33^{\circ} \mathrm{C}$ with constant oxygenation, and transferred to oxygenated standard aCSF (in mM: $\mathrm{NaCl} 120, \mathrm{KCl} 3.5, \mathrm{NaH} 2 \mathrm{PO} 41.25, \mathrm{NaHCO} 325$, glucose 10, $\mathrm{MgCl} 21, \mathrm{CaCl} 22$ ) solution for at least 1 hour at room temperature. Slices were transferred to a submersion recording chamber and were continuously perfused at a rate of $4-5 \mathrm{ml} / \mathrm{min}$ with fully oxygenated aCSF at room temperature. For whole-cell recording, patch pipettes at 4-6 $\mathrm{M} \Omega$ were pulled from borosilicate glass capillaries $(1.5 \mathrm{~mm}$ OD, $0.86 \mathrm{~mm}$ ID, Harvard Apparatus, \#GC150F-10) and filled with intracellular solution containing (in $\mathrm{mM}: 128$ $\mathrm{CsCH}_{3} \mathrm{SO}_{3}, 2.8 \mathrm{NaCl}, 20$ HEPES, 0.4 EGTA, 5 TEA-Cl, 2 Mg-ATP, $0.5 \mathrm{NaGTP}$ (pH 7.35, osmolality $285 \mathrm{mOsm}) .0 .1 \%$ Neurobiotin was included in the intracellular solutions to identify 
bioRxiv preprint doi: https//doi.org/10.1101/2020.10.19.345728; this version posted October 20, 2020. The copyright holder for this preprint (which was not certified by peer review) is the author/funder, who has granted bioRxiv a license to display the preprint in perpetuity. It is made available under aCC-BY-NC 4.0 International license.

the cell position and morphology following recording. Recordings were performed using a Multiclamp 700B amplifier (Molecular Devices. CA). Access and input resistances were monitored throughout the experiments. The access resistance was typically $<20 \mathrm{M} \Omega$, and results we discarded if resistance changed by more than $20 \%$.

GFP+ neurons were visually identified and randomly selected. For AMPA and NMDA current, a bipolar stimulus microelectrode (MX21AEW, FHC) was placed 100-200um away from recording site caudally. The intensity of stimulus (10ms) was adjusted to evoke a measurable, evoked EPSC in recording cells. AMPA and NMDA mixed currents were measured at a holding potential of $+40 \mathrm{mV}$. After obtaining at least 10 sweeps of stable mixed currents, D-AP5 $(50 \mu \mathrm{M})$ was perfused to bath solution for $15 \mathrm{~min}$ and AMPA currents were measured. NMDA currents were obtained by subtracting AMPA currents from mixed currents off-line. The peak amplitude of both currents was used for AMDA/NMDA ratio analysis. For sEPSCs, GFP+ LPO neurons were voltage clamped at $-70 \mathrm{mV}$ constantly. A stable baseline recording was obtained for 5-10 min. Frequency, amplitude, rise \& decay time constants of sEPSCs were analysed off-line with the Mini Analysis (Synaptosoft). Frequency was obtained from 2 min of recording. All recordings were made under the presence of picrotoxin $(100 \mu \mathrm{M})$.

For immunohistochemistry following electrophysiological recordings, brain slices were post-fixed in $4 \%$ PFA overnight at $4{ }^{\circ} \mathrm{C}$. PFA was then washed away 3 times for $10 \mathrm{~min}$ in $1 \mathrm{x}$ PBS and slices were blocked and permeabilized in $20 \%$ NGS or $2 \%$ Bovine Serum Albumin (BSA) for 3 hours shaking. Primary anti-GFP Ab to trace viral distribution was diluted in $2 \%$ NGS, $0.5 / 0.7 \%$ TritonX in PBS overnight at $4^{\circ} \mathrm{C}$ shaking. After 4 washes in $1 \times$ PBS fpr $10 \mathrm{~min}$ each, secondary Ab was diluted in $2 \%$ NGS and $0.5 \%$ TritonX for 3 hours at RT and shaking. After washes and to track Neruobiotin filled neurons recorded by electrophysiology, an Alexa594-conjugated streptavidin (Invitrogen) was diluted 1:500 in 1\% NGS, 0.5\% TritonX and slices were incubated for 2-3 hours at RT. 4 washes of $15 \mathrm{~min}$ and subsequent DAPI incubation for $10 \mathrm{~min}$ were performed before slices were mounted on glass slides as described in Section 2.8. 


\section{Calcium Photometry}

Following 4 weeks of recovery, mice were acclimatized to the testing environment for at least 2 hours before behavioural experiments and then recorded for 6 hours during the light period. As light source, a Grass SD9 stimulator was used to control a $473 \mathrm{~nm}$ Diode-pumped solid state (DPSS) laser with fibre coupler (Shanghai Laser \& Optics century Co.) and adjustable power supply (Shanghai Laser \& Optics century Co.). A lock-in amplifier (SR810, Stanford Research Systems, California, USA) was used to drive the laser at $125 \mathrm{~Hz}$ TTL pulsations with an average power of $80 \mu \mathrm{W}$ at the tip of the fibre directly connected to the mouse. The light source was joined to a fluorescence cube (FMC_GFP_FC, Doric Lenses) through an optical fibre patch cord ( $\varnothing 200 \mu \mathrm{m}, 0.22$ NA, Doric Lenses). From the filter cube, an optical patch cords ( $\varnothing 200 \mu \mathrm{m}, 0.37$ NA, Doric Lenses) was connected to the monofibre chronically implanted in the mouse brain using a ceramic sleeves (Thorlabs). The GCaMP6s output was then filtered at 500-550 nm through the fluorescence cube, converted in Volts by a photodiode (APD-FC, Doric Lenses) and then amplified by the lock-in amplifier with a time constant of 30ms. Finally, the signal was digitalized using a CED 1401 Micro box (Cambridge Electronic Design, Cambridge, UK) and recorded at $200 \mathrm{~Hz}$ using Spike2 software (Cambridge Electronic Design, Cambridge, UK). Photometry, EEG and EMG data were aligned offline using Spike2 software and analyzed using custom made MATLAB (MathWorks) scripts. For each experiment, the photometry signal $F$ was normalized to baseline using the function $\Delta F / F$ $=\left(F-F_{0}\right) / F_{0}$, where $F_{0}$ is the mean fluorescence across the signal analyzed.

\section{Generation of shRNAs to target GluN1}

We used the potent $\underline{R} N A$ interference using microRNA expression (PRIME) system, where shRNAs are placed into the context of mir30 microRNA sequence (Stegmeier et al., 2005). By consulting the website http://katahdin.cshl.org, three shRNAs were designed to target exons 11 to 18 of the Grin1 gene, encoding the region from amino acids 409 to 683 of GluN1. The sequences were amplified from mouse genomic DNA using primers (pSM2C Forward: 5'- 
GATGGCTG-CTCGAG-AAGGTATAT-TGCTGTTGACAGTGAGCG-3'; pSM2C Reverse: 5'GTCTAGAG-GAATTC-CGAGGCAGTAGGCA-3'), following the protocol previously described (Stegmeier et al., 2005).

The three sequences were referred as shRNA-GluN1-1.1, -2 or -3 (the underlined sequences are the 22 mers specific for the GluN1 subunit):

shRNA-GluN1.1 targeted the GluN1 sequence at 1800bp (600aa) of the CDS: 3'TGCTGTTGACAGTGAGCGAACTGACCCTGTCCTCTGCCATTAGTGAAGCCACAGATGTA ATGGCAGAGGACAGGGTCAGTGTGCCTACTGCCTCGGA-5'

shRNA-GluN1.2 matched the GluN1 sequence from 2565bp (855aa) of the CDS: 3'TGCTGTTGACAGTGAGCGCGCCGTGAACGTGTGGAGGAAGTAGTGAAGCCACAGATGT ACTTCCTCCACACGTTCACGGCTTGCCTACTGCCTCGGA-5’

shRNA-GIN1.3 targeted the GluN1 sequence at 2215bp (738aa) of the CDS: 3'TGCTGTTGACAGTGAGCGCGGAGTTTGAGGCTTCACAGAATAGTGAAGCCACAGATGT

\section{ATTCTGTGAAGCCTCAAACTCCATGCCTACTGCCTCGGA-5'}

As control for shRNA-GluN1 sequences, an shRNA scramble hairpin was also produced, making sure it would not be complementary to any sequences in the mouse DNA. The shRNAscramble sequence was:

3'-

\section{GCTGTTGACAGTGAGCGAGCTCCCTGAATTGGAATCCTAGTGAAGCCACAGATGTAGG}

\section{ATTCCAATTCAGCGGGAGCCTGCCTACTGCCTCGGA-5’.}

The three shRNA-GluN1 hairpins and the shRNA-scramble hairpin were cloned into the pPRIME vector in the context of the mir30 micro RNA sequence, to be then expressed and tested in HEK293 cells. To establish shRNA efficiencies in knocking down the NMDA GluN1 subunit expression, a plasmid was constructed expressing GluN1-2A-mCherry under the control of the CMV promoter. Each GluN1 shRNA pPRIME plasmid was then transfected into HEK293 cells together with pGluN1-2A-mCherry. After 60 hours in culture, cherry red fluorescence was quantified. The GluN1.3 shRNA produced lower fluorescence intensity, and 
thus higher inhibition of GluN1 expression, and it was therefore cloned into an AAV transgene in an inverse orientation flanked by lox sites, as we described previously (Yu et al., 2015), to produce $A A V$-flex-shRNA-GluN1. The transgene expresses GFP as well as shRNA-GluN1.

\section{STATISTICAL ANALYSIS}

Origin, MATLAB and GraphPad Prism 8 ware used for graphs and statistical analysis. Data collection and experimental procedure conditions were randomized. The experimenter was not blinded during the procedures. Data are presented as mean \pm standard error of the means (SEM). Normality of each data set distribution was tested using the Kolmogorov-Smirnoff test. Unpaired two-tailed Student's $t$ test or one-way ANOVA were used to compare groups when only one variable was present. For measurement and data collected over time or with two separate independent variables, a 2-way repeated measures (RM) ANOVA or a simple 2-way ANOVA followed by post-hoc Sidak or Tukey tests were performed. When data did not result as normally distributed, Mann-Whitney test was performed. All details of statistical analyses used are specified in each figure legend. Statistical significance was considered when ${ }^{*} P<$ 0.05 


\section{REFERENCES}

Abraham, N.M., Egger, V., Shimshek, D.R., Renden, R., Fukunaga, I., Sprengel, R., Seeburg, P.H., Klugmann, M., Margrie, T.W., Schaefer, A.T., et al. (2010). Synaptic inhibition in the olfactory bulb accelerates odor discrimination in mice. Neuron 65, 399-411.

Adams, R., Brown, G.T., Davidson, M., Fisher, E., Mathisen, J., Thomson, G., and Webster, N.R. (2013). Efficacy of dexmedetomidine compared with midazolam for sedation in adult intensive care patients: a systematic review. Br J Anaesth 111, 703-710.

Akeju, O., Hobbs, L.E., Gao, L., Burns, S.M., Pavone, K.J., Plummer, G.S., Walsh, E.C., Houle, T.T., Kim, S.E., Bianchi, M.T., et al. (2018). Dexmedetomidine promotes biomimetic non-rapid eye movement stage 3 sleep in humans: A pilot study. Clin Neurophysiol 129, 6978.

Anisimov, V.N., Herbst, J.A., Abramchuk, A.N., Latanov, A.V., Hahnloser, R.H., and Vyssotski, A.L. (2014). Reconstruction of vocal interactions in a group of small songbirds. Nat Methods $11,1135-1137$.

Arino, H., Munoz-Lopetegi, A., Martinez-Hernandez, E., Armangue, T., Rosa-Justicia, M., Escudero, D., Matos, N., Graus, F., Sugranyes, G., Castro-Fornieles, J., et al. (2020). Sleep disorders in anti-NMDAR encephalitis. Neurology 95, e671-e684.

Borbely, A.A., Daan, S., Wirz-Justice, A., and Deboer, T. (2016). The two-process model of sleep regulation: a reappraisal. J Sleep Res 25, 131-143.

Boyce, R., Glasgow, S.D., Williams, S., and Adamantidis, A. (2016). Causal evidence for the role of REM sleep theta rhythm in contextual memory consolidation. Science 352, 812-816.

Burgdorf, J.S., Vitaterna, M.H., Olker, C.J., Song, E.J., Christian, E.P., Sorensen, L., Turek, F.W., Madsen, T.M., Khan, M.A., Kroes, R.A., et al. (2019). NMDAR activation regulates the daily rhythms of sleep and mood. Sleep 42.

Chen, K.S., Xu, M., Zhang, Z., Chang, W.C., Gaj, T., Schaffer, D.V., and Dan, Y. (2018). A Hypothalamic Switch for REM and Non-REM Sleep. Neuron 97, 1168-1176 e1164.

Chen, T.W., Wardill, T.J., Sun, Y., Pulver, S.R., Renninger, S.L., Baohan, A., Schreiter, E.R., Kerr, R.A., Orger, M.B., Jayaraman, V., et al. (2013). Ultrasensitive fluorescent proteins for imaging neuronal activity. Nature 499, 295-300. 
Chung, S., Weber, F., Zhong, P., Tan, C.L., Nguyen, T.N., Beier, K.T., Hormann, N., Chang, W.C., Zhang, Z., Do, J.P., et al. (2017). Identification of preoptic sleep neurons using retrograde labelling and gene profiling. Nature 545, 477-481.

Cui, Y., Hu, S., and Hu, H. (2019). Lateral Habenular Burst Firing as a Target of the Rapid Antidepressant Effects of Ketamine. Trends Neurosci 42, 179-191.

Dalmau, J., Armangue, T., Planaguma, J., Radosevic, M., Mannara, F., Leypoldt, F., Geis, C., Lancaster, E., Titulaer, M.J., Rosenfeld, M.R., et al. (2019). An update on anti-NMDA receptor encephalitis for neurologists and psychiatrists: mechanisms and models. Lancet Neurol 18, 1045-1057.

Della Monica, C., Johnsen, S., Atzori, G., Groeger, J.A., and Dijk, D.J. (2018). Rapid Eye Movement Sleep, Sleep Continuity and Slow Wave Sleep as Predictors of Cognition, Mood, and Subjective Sleep Quality in Healthy Men and Women, Aged 20-84 Years. Front Psychiatry 9, 255.

Gelegen, C., Gent, T.C., Ferretti, V., Zhang, Z., Yustos, R., Lan, F., Yang, Q., Overington, D.W., Vyssotski, A.L., van Lith, H.A., et al. (2014). Staying awake--a genetic region that hinders alpha2 adrenergic receptor agonist-induced sleep. Eur J Neurosci 40, 2311-2319.

Gelegen, C., Miracca, G., Ran, M.Z.Z., Harding, E.C., Ye, Z.W., Yu, X., Tossell, K., Houston, C.M., Yustos, R., Hawkins, E.D., et al. (2018). Excitatory Pathways from the Lateral Habenula Enable Propofol-Induced Sedation. Current Biology 28, 580-+.

Izawa, S., Chowdhury, S., Miyazaki, T., Mukai, Y., Ono, D., Inoue, R., Ohmura, Y., Mizoguchi, H., Kimura, K., Yoshioka, M., et al. (2019). REM sleep-active MCH neurons are involved in forgetting hippocampus-dependent memories. Science $365,1308-+$.

Jego, S., Glasgow, S.D., Herrera, C.G., Ekstrand, M., Reed, S.J., Boyce, R., Friedman, J., Burdakov, D., and Adamantidis, A.R. (2013). Optogenetic identification of a rapid eye movement sleep modulatory circuit in the hypothalamus. Nat Neurosci 16, 1637-1643.

Klugmann, M., Symes, C.W., Leichtlein, C.B., Klaussner, B.K., Dunning, J., Fong, D., Young, D., and During, M.J. (2005). AAV-mediated hippocampal expression of short and long Homer 1 proteins differentially affect cognition and seizure activity in adult rats. Mol Cell Neurosci 28, 347-360. 
Krashes, M.J., Koda, S., Ye, C., Rogan, S.C., Adams, A.C., Cusher, D.S., Maratos-Flier, E., Roth, B.L., and Lowell, B.B. (2011). Rapid, reversible activation of AgRP neurons drives feeding behavior in mice. J Clin Invest 121, 1424-1428.

Kroeger, D., Absi, G., Gagliardi, C., Bandaru, S.S., Madara, J.C., Ferrari, L.L., Arrigoni, E., Munzberg, H., Scammell, T.E., Saper, C.B., et al. (2018). Galanin neurons in the ventrolateral preoptic area promote sleep and heat loss in mice. Nat Commun 9, 4129.

Leshan, R.L., Greenwald-Yarnell, M., Patterson, C.M., Gonzalez, I.E., and Myers, M.G., Jr. (2012). Leptin action through hypothalamic nitric oxide synthase-1-expressing neurons controls energy balance. Nat Med 18, 820-823.

Li, W.C., Roberts, A., and Soffe, S.R. (2010). Specific Brainstem Neurons Switch Each Other into Pacemaker Mode to Drive Movement by Activating NMDA Receptors. Journal of Neuroscience 30, 16609-16620.

Liu, S., Liu, Q., Tabuchi, M., and Wu, M.N. (2016). Sleep Drive Is Encoded by Neural Plastic Changes in a Dedicated Circuit. Cell 165, 1347-1360.

Lu, J., Bjorkum, A.A., Xu, M., Gaus, S.E., Shiromani, P.J., and Saper, C.B. (2002). Selective activation of the extended ventrolateral preoptic nucleus during rapid eye movement sleep. Journal of Neuroscience 22, 4568-4576.

Lu, J., Greco, M.A., Shiromani, P., and Saper, C.B. (2000). Effect of lesions of the ventrolateral preoptic nucleus on NREM and REM sleep. J Neurosci 20, 3830-3842.

Luppi, P.H., Billwiller, F., and Fort, P. (2017). Selective activation of a few limbic structures during paradoxical (REM) sleep by the claustrum and the supramammillary nucleus: evidence and function. Curr Opin Neurobiol 44, 59-64.

Ma, Y., Miracca, G., Yu, X., Harding, E.C., Miao, A., Yustos, R., Vyssotski, A.L., Franks, N.P., and Wisden, W. (2019). Galanin Neurons Unite Sleep Homeostasis and alpha2-Adrenergic Sedation. Curr Biol 29, 3315-3322 e3313.

McGinty, D.J., and Sterman, M.B. (1968). Sleep suppression after basal forebrain lesions in the cat. Science $160,1253-1255$.

Monyer, H., Burnashev, N., Laurie, D.J., Sakmann, B., and Seeburg, P.H. (1994). Developmental and regional expression in the rat brain and functional properties of four NMDA receptors. Neuron 12, 529-540. 
Monyer, H., Sprengel, R., Schoepfer, R., Herb, A., Higuchi, M., Lomeli, H., Burnashev, N., Sakmann, B., and Seeburg, P.H. (1992). Heteromeric NMDA receptors: molecular and functional distinction of subtypes. Science 256, 1217-1221.

Moriyoshi, K., Masu, M., Ishii, T., Shigemoto, R., Mizuno, N., and Nakanishi, S. (1991). Molecular cloning and characterization of the rat NMDA receptor. Nature 354, 31-37.

Nauta, W.J. (1946). Hypothalamic regulation of sleep in rats; an experimental study. J Neurophysiol 9, 285-316.

Niwa, Y., Kanda, G.N., Yamada, R.G., Shi, S., Sunagawa, G.A., Ukai-Tadenuma, M., Fujishima, H., Matsumoto, N., Masumoto, K.H., Nagano, M., et al. (2018). Muscarinic Acetylcholine Receptors Chrm1 and Chrm3 Are Essential for REM Sleep. Cell Rep 24, 22312247 e2237.

Paoletti, P., Bellone, C., and Zhou, Q. (2013). NMDA receptor subunit diversity: impact on receptor properties, synaptic plasticity and disease. Nat Rev Neurosci 14, 383-400.

Peever, J., and Fuller, P.M. (2016). Neuroscience: A Distributed Neural Network Controls REM Sleep. Curr Biol 26, R34-35.

Raccuglia, D., Huang, S., Ender, A., Heim, M.M., Laber, D., Suarez-Grimalt, R., Liotta, A., Sigrist, S.J., Geiger, J.R.P., and Owald, D. (2019). Network-Specific Synchronization of Electrical Slow-Wave Oscillations Regulates Sleep Drive in Drosophila. Curr Biol 29, 36113621 e3613.

Reichert, S., Pavon Arocas, O., and Rihel, J. (2019). The Neuropeptide Galanin Is Required for Homeostatic Rebound Sleep following Increased Neuronal Activity. Neuron 104, 370-384 e375.

Renouard, L., Billwiller, F., Ogawa, K., Clement, O., Camargo, N., Abdelkarim, M., Gay, N., Scote-Blachon, C., Toure, R., Libourel, P.A., et al. (2015). The supramammillary nucleus and the claustrum activate the cortex during REM sleep. Sci Adv 1, e1400177.

Roth, T., Coulouvrat, C., Hajak, G., Lakoma, M.D., Sampson, N.A., Shahly, V., Shillington, A.C., Stephenson, J.J., Walsh, J.K., and Kessler, R.C. (2011). Prevalence and perceived health associated with insomnia based on DSM-IV-TR; International Statistical Classification of Diseases and Related Health Problems, Tenth Revision; and Research Diagnostic Criteria/International Classification of Sleep Disorders, Second Edition criteria: results from the America Insomnia Survey. Biol Psychiatry 69, 592-600. 
Schmidt, E.F., Kus, L., Gong, S., and Heintz, N. (2013). BAC transgenic mice and the GENSAT database of engineered mouse strains. Cold Spring Harb Protoc 2013.

Shahid, A., Chung, S.A., Phillipson, R., and Shapiro, C.M. (2012). An approach to long-term sedative-hypnotic use. Nat Sci Sleep 4, 53-61.

Sherin, J.E., Shiromani, P.J., McCarley, R.W., and Saper, C.B. (1996). Activation of ventrolateral preoptic neurons during sleep. Science 271, 216-219.

Steenland, H.W., Liu, H., and Horner, R.L. (2008). Endogenous glutamatergic control of rhythmically active mammalian respiratory motoneurons in vivo. J Neurosci $28,6826-6835$.

Stegmeier, F., Hu, G., Rickles, R.J., Hannon, G.J., and Elledge, S.J. (2005). A lentiviral microRNA-based system for single-copy polymerase II-regulated RNA interference in mammalian cells. Proc Natl Acad Sci U S A 102, 13212-13217.

Szymusiak, R., Gvilia, I., and McGinty, D. (2007). Hypothalamic control of sleep. Sleep Med 8, 291-301.

Tatsuki, F., Sunagawa, G.A., Shi, S., Susaki, E.A., Yukinaga, H., Perrin, D., Sumiyama, K., Ukai-Tadenuma, M., Fujishima, H., Ohno, R., et al. (2016). Involvement of Ca(2+)-Dependent Hyperpolarization in Sleep Duration in Mammals. Neuron 90, 70-85.

Tobler, I., Deboer, T., and Fischer, M. (1997). Sleep and sleep regulation in normal and prion protein-deficient mice. J Neurosci 17, 1869-1879.

Tomita, J., Ueno, T., Mitsuyoshi, M., Kume, S., and Kume, K. (2015). The NMDA Receptor Promotes Sleep in the Fruit Fly, Drosophila melanogaster. PLoS One 10, e0128101.

Tsien, J.Z., Huerta, P.T., and Tonegawa, S. (1996). The essential role of hippocampal CA1 NMDA receptor-dependent synaptic plasticity in spatial memory. Cell 87, 1327-1338.

Van Someren, E.J.W. (2020). Brain mechanisms of insomnia: new perspectives on causes and consequences. Physiol Rev.

Vong, L., Ye, C., Yang, Z., Choi, B., Chua, S., Jr., and Lowell, B.B. (2011). Leptin action on GABAergic neurons prevents obesity and reduces inhibitory tone to POMC neurons. Neuron $71,142-154$. 
Vyssotski, A.L., Dell'Omo, G., Dell'Ariccia, G., Abramchuk, A.N., Serkov, A.N., Latanov, A.V., Loizzo, A., Wolfer, D.P., and Lipp, H.P. (2009). EEG responses to visual landmarks in flying pigeons. Curr Biol 19, 1159-1166.

Wisden, W., Yu, X., and Franks, N.P. (2019). GABA Receptors and the Pharmacology of Sleep. Handb Exp Pharmacol 253, 279-304.

Yamada, R.G., and Ueda, H.R. (2019). Molecular Mechanisms of REM Sleep. Front Neurosci 13, 1402.

Yang, Y., Cui, Y.H., Sang, K.N., Dong, Y.Y., Ni, Z.Y., Ma, S.S., and Hu, H.L. (2018). Ketamine blocks bursting in the lateral habenula to rapidly relieve depression. Nature 554, 317-+.

Yoder, R.M., and Pang, K.C.H. (2005). Involvement of GABAergic and cholinergic medial septal neurons in hippocampal theta rhythm. Hippocampus 15, 381-392.

Yu, X., Ye, Z., Houston, C.M., Zecharia, A.Y., Ma, Y., Zhang, Z., Uygun, D.S., Parker, S., Vyssotski, A.L., Yustos, R., et al. (2015). Wakefulness Is Governed by GABA and Histamine Cotransmission. Neuron 87, 164-178.

Zhang, Z., Ferretti, V., Guntan, I., Moro, A., Steinberg, E.A., Ye, Z., Zecharia, A.Y., Yu, X., Vyssotski, A.L., Brickley, S.G., et al. (2015). Neuronal ensembles sufficient for recovery sleep and the sedative actions of alpha2 adrenergic agonists. Nat Neurosci 18, 553-561. 